Research Article

\title{
Seismic Performance of Steel Box Bridge Piers with Earthquake-Resilient Function
}

\author{
Haifeng Li ${ }^{D}{ }^{1,2}{ }^{1,2}$ Wenwei Luo, ${ }^{1}$ and Jun Luo ${ }^{1}$ \\ ${ }^{1}$ College of Civil Engineering, Huaqiao University, Xiamen 361021, China \\ ${ }^{2}$ Key Laboratory for Intelligent Infrastructure and Monitoring of Fujian Province (Huaqiao University), Xiamen 361021, China
}

Correspondence should be addressed to Haifeng Li; lihai_feng@126.com

Received 7 March 2020; Revised 28 June 2020; Accepted 3 July 2020; Published 12 August 2020

Academic Editor: Valeria Vignali

Copyright (c) 2020 Haifeng Li et al. This is an open access article distributed under the Creative Commons Attribution License, which permits unrestricted use, distribution, and reproduction in any medium, provided the original work is properly cited.

A novel steel box bridge pier with replaceable energy dissipation wall plates at the base was proposed. After moderate earthquakes, the damaged energy dissipation wall plates and constraining steel plates on the two sides could be rapidly replaced, while the entire energy-dissipated column at the base can also be replaced after rare earthquakes. In this way, the seismic capacity of the new type of steel box bridge pier could be restored after earthquakes. For the purpose of discussing the seismic performance of this novel steel box-shaped bridge pier, the pseudostatic test and numerical simulation were performed. The results showed that the failure of the specimens in the pseudostatic tests occurred predominantly in the energy dissipation zone at the base. After replacing the damaged energy-dissipated column at the base, the seismic behavior of the proposed steel bridge pier can be recovered rapidly. Axial compression ratio is an important factor influencing the seismic behavior of the novel steel box bridge pier. The strength of the energy dissipation wall plates influences the novel steel box-shaped bridge pier's bearing capacity and deformation capacity. Spacing between the horizontal stiffening ribs had little impact on the bearing capacity and deformation capacity of the proposed steel bridge pier. The larger the thickness of the energy dissipation wall plate, the higher the bearing capacity and deformation capacity of the steel box bridge pier. Finally, an empirical equation for the design of this novel steel bridge pier under cyclic loading was proposed.

\section{Introduction}

Owing to rapid urban development, steel box bridge piers have been increasingly applied to overpass projects. Steel box bridge piers have the advantages of low deadweight, ease of mass production, and easy assembly, which can help shorten the construction time and improve onsite operation conditions. However, after major earthquakes, these steel box bridge piers may show local buckling and weld failure. Extensive research has been conducted on the mechanical properties and seismic reinforcement of the steel box bridge pier. It has been recognized that the use of stiffening ribs at the base of the steel box bridge piers can improve their seismic performance. Al-Kaseasbeh and Mamaghani [1] studied the thin-walled box-shaped steel bridge piers with stiffening ribs, in which the thickness of the box-shaped wall plates varied within different ranges. They simulated the hysteretic performance of such steel box bridge piers and proposed simplified formula for the buckling bearing capacity and ductility. Kang et al. [2] investigated the hysteretic performance of high-strength steel box bridges with stiffening ribs and discussed the application of SM570 in the steel bridge pier. Chen et al. [3] conducted a numerical simulation on the steel box bridge piers with stiffening ribs to discuss its hysteretic performance and proposed a hysteresis model considering the local buckling of steel plates. Nishikawa et al. [4] discussed methods of seismic reinforcement for steel box bridge piers by using vertical stiffening ribs and angle steel, and they further conducted a pseudostatic test on the steel box bridge pier. Hsu and Chang [5] proposed installing a steel frame on the base of the steel box bridge pier for seismic reinforcement and performed a pseudostatic test on 12 similar samples. Ismail et al. [6] studied steel box bridge piers with stiffening ribs and 
performed a numerical analysis of the dynamic response under the action of different seismic waves. Aoki et al. [7] studied framed steel bridge piers with vertical stiffening ribs and discussed the influence of stiffening ribs on the seismic performance of framed steel bridge piers with vertical stiffening ribs. Gao et al. [8] focused on the steel box-shaped piers which have stiffening ribs inside and conducted a numerical analysis on steel box bridge piers under eccentric pressure on column top and horizontal cyclic loading. They then proposed a simplified formula for bearing capacity and deformation. Ge and Kang [9] studied the thick-walled steel box bridge piers without stiffening ribs and conducted the superlow cycle fatigue test under low-cyclic loading. They further discussed the influence pattern of random cyclic loading on the evolution of plastic cracking.

Steel box bridge piers with concrete-filled base have better seismic performance. Usami et al. $[10,11]$ performed an experimental study on box-shaped steel bridge piers with partial concrete-filled and discussed the influence patterns of concrete filling on the seismic behavior of box-shaped steel piers. Ge et al. [12] conducted the numerical analysis on partial concrete-filled steel bridge piers having box section and proposed a calculation method for the deformation of such piers. Goto et al. [13] studied concrete-filled steel bridge piers of box section with vertical stiffening ribs, built a numerical model for analyzing the hysteresis of such steel bridge piers, verified the accuracy of the nonlinear finite element model, and analyzed the test results. Susantha et al. [14] performed a numerical simulation on concrete-filled box steel columns and proposed a calculation method for the change law of strength and ductility of such steel box-shaped columns. Nakanishi et al. [15] conducted an experiment on the strength and ductility of concrete-filled box steel columns. Yamao et al. [16] discussed the influence pattern of cross-shaped stiffening ribs on the hysteresis of the steel bridge piers. Dang and Aoki [17] discussed the seismic response of steel bridge piers under bidirectional seismic action.

For the purpose of regaining the seismic performance of steel bridge piers after earthquakes rapidly, methods of installing specific energy dissipation components at the steel piers' bottom have been studied for seismic reinforcement. El-Bahey and Bruneau $[18,19]$ suggested installing specific energy dissipation components between double-column steel bridge piers and carried out experiment and numerical simulation analyses on such steel bridge piers. Susantha et al. [20] proposed the installation of low-yield-point steel wall plates at the base of the steel piers and then experimented with this idea. They discussed the method of improving the steel piers' ductility by using the low-yield-point steel. By weakening the vertical stiffening ribs at specific positions, Chen and Chen [21] produced plastic energy dissipation zones at certain positions such as the steel piers' bottom. The seismic behavior of such steel bridge piers was tested. Kitada et al. [22] proposed installing specific energy dissipation zones to the base of the steel bridge piers as a way of boosting the seismic performance and verified this method through experiments. Li et al. [23, 24] carried out experimental study and numerical analysis on seismic performance of the new type of box-shaped steel bridge pier with energy-dissipating shell plates. Other earthquake-resilient structures are also discussed frequently, for example, Jiang et al. [25, 26] tested seismic behavior of earthquake-resilient prefabricated cross joints. In addition, Chen and Sudibyo [27] conducted an experimental study of eight $\mathrm{PE}$ beams under cyclic loading to test the effectiveness of intermediate stiffeners. Choo et al. [28] examined the flexural behavior of concrete beams reinforced with the hybrid FRP-steel rebar and evaluated their fatigue performance.

By replacing the energy dissipation components at the steel bridge piers' bottom, the novel type of steel bridge pier with fast recoverable function after an earthquake is developed. This has become a research focus in the field of bridge engineering. In this study, we propose a novel steel box bridge pier with earthquake-resilient function, that is, a specific energy dissipation zone with replaceable components which installed at the bottom of box-shaped steel bridge piers. This energy dissipation zone was mainly composed of low-yield-point steel energy dissipation wall plates, surrounded by constraining steel plates. After moderate earthquakes, the damaged low-yield-point steel energy dissipation wall plates and the surrounding constraining steel plates can be rapidly replaced. After rare earthquakes, the entire energy dissipation zone at the base can be also replaced, and the seismic resistance of the steel bridge piers can be recovered rapidly. However, installing the energy dissipation zone at the base will alter the force transfer mechanism and failure mode of steel bridge piers. The present study attempts to discuss the seismic behavior of this novel type of box-shaped steel bridge piers by conducting following tests: (a) pseudostatic tests were performed to analyze the failure features, load-displacement curve and the corresponding skeleton curve, bearing capacity, capacity of deformation, stiffness and strength degradation, and capacity of energy dissipation for the test specimens in addition to discussing the influence of installing the energy dissipation zone, axial compression ratio, and eccentricity on the seismic performance of the specimens in the pseudostatic test; (b) numerical simulation was performed and the results were compared against those from the pseudostatic tests so as to verify the accuracy of the finite element model. On this basis, the influence of axial compression ratio, strength, and thickness of energy dissipation plates with low-yield-point steel, spacing between horizontal stiffening ribs, and eccentricity on the skeleton curve of the test specimen in the numerical simulation were discussed; (c) the test results and finite element analysis results were analyzed comprehensively. Thus, a design formula for the bearing capacity of the novel box-shaped steel bridge piers under cyclic loading was proposed.

\section{Experimental Program}

2.1. Specimen Design. For the pseudostatic test, three groups of test specimens, namely I, II, and III, were used, and there were seven specimens in total. Each specimen was composed of an upper column on top, a replaceable energy-dissipated column at the base, and a rigid base. The spatial relationship 
between the existing equipment in the laboratory, loading capacity of the servo loading system, and the use of a data sampling device were taken into account. The scale used for the test specimens was $1: 4$. The cross-sectional area of all three groups of specimens was $375 \times 375 \times 6 \times 6 \mathrm{~mm}$. For the energy dissipation wall plate at the base, the low-yield-point steel LYP100 was used; for other wall plates, Q345 steel was used. For group I, only the specimen I-1 installed stiffening ribs in both horizontal and vertical direction at the base. The thickness of the stiffening ribs was $6 \mathrm{~mm}$ and $50 \mathrm{~mm}$ for the width, and the ribs were made of Q345 steel. Group II consisted of three specimens, where replaceable bucklingrestrained energy dissipation wall plates were installed on the base. On the two sides of the low-yield-point steel energy dissipation wall plates, there were constraining steel plates surrounding them, which were connected via high-strength bolts. The configuration of the three specimens was the same except for the axial compression ratio. Group III consisted of three specimens. The eccentricity of vertical loading on the column top was $80 \mathrm{~mm}$ for all samples, though the axial compression ratio of each specimen differed. The configuration of specimens in group III was the same as that in group II.

Specimens used for the pseudostatic test are shown in Figure 1, and their design parameters are summarized in Table 1. In Figure 1, (1) is the ordinary steel wall plate; (2) is the vertical stiffening rib; (3) is the horizontal stiffening rib; (4) is the low-yield-point steel energy dissipation wall plate; (5) is the constraining steel plate on the two sides; and (6) is the high-strength bolt. In Table $1, L$ is the height of the specimen; $D L$ is the height of the energy dissipation zone; $h$ is the height of the cross section, and $b$ means width of the cross section, respectively; $t$ is the wall plate thickness; $b_{1}$ is the width of the energy dissipation wall plate; $t_{1}$ is the thickness of the energy dissipation wall plate; $D S_{1}$ is the spacing between the horizontal stiffening ribs; $e$ is the eccentricity of vertical loading $N ; n$ is the axial compression ratio, $n=N / f A, f$ is the strength of the ordinary steel wall plate, $A$ is cross-sectional area of the pseudostatic specimen.

As shown in Figure 1(e), the energy-dissipated zone of group II and group III is composed of low-yield-point (LYP) steel plates, ordinary steel wall plates, stiffening ribs, and constraining steel plates. The stiffening ribs and LYP steel plates were connected with the ordinary steel plates by welding. The constraining steel plates were added on both sides of the wall plates to restrain the deformation of LYP steel plates, and the LYP steel plates, wall plates, and constraining steel plates are connected by high-strength bolts.

2.2. Test Setup. A pseudostatic test was undertaken at the structural engineering laboratory of the School of Civil Engineering at Huaqiao University. The loading system and photos of onsite loading are shown in Figure 2.

Horizontal cyclic loading on the column top was imposed with displacement control. The horizontal loading scheme on the column top was as follows: the initial loading was applied at the levels of $0.5 \delta_{\mathrm{y}}$ and $0.75 \delta_{\mathrm{y}}$, for one cycle at each level; this was followed by the formal loading, at the level of $1 \delta_{\mathrm{y}}, 2 \delta_{\mathrm{y}}, 3 \delta_{\mathrm{y}} \ldots$, for three cycles at each level. $\delta_{\mathrm{y}}$ is the lateral displacement of the column top corresponding to the yield of fibers at the margin of the specimen base. The horizontal loading scheme on the column top is shown in Figure 3.

2.3. Material Properties. Two types of steel plates were used for the pseudostatic test, namely, Q345 steel of $6 \mathrm{~mm}$ thickness and LYP100 steel of $14 \mathrm{~mm}$ thickness. For each specification, three specimens were prepared. The design specification of the material specimens is shown in Figure 4, and the loading equipment used for the material test is shown in Figure 5.

Photographs of the material specimens before stretching and after fracture are shown in Figure 6. The test results related to plate thickness, yield strength, tensile strength, and percentage elongation after fracture are provided in Table 2.

\section{Experimental Results and Discussion}

3.1. Failure Models. The final failure mode of the test specimens is shown in Figure 7. The damage is sustained by the energy dissipation zone at the base in all the specimens, and the upper pier column and rigid base can be used repeatedly. This indicates that by replacing the damaged energy dissipation zone at the base, the seismic design of a steel box bridge pier with earthquake-resilient function can be achieved. There were two failure modes of specimens in the pseudostatic test: one was local buckling at the wall plate of the specimen and the predominant failure mode was plastic deformation; the other was weld failure or fracture of the wall plate at the corner in the energy dissipation zone at the base. Plastic deformation of the specimens in the pseudostatic test occurred mainly near the base of the rigid support. After installing the buckling-restrained energy dissipation wall plates, the buckling deformation of the specimen decreased, while the deformation capacity increased to a certain extent.

\subsection{Hysteresis Curves. Figure 8 shows the load-displacement} hysteresis curve of the pseudostatic test specimens. The $Y$ axis represented the cyclic load $V$ on the top of the column in horizontal direction, while the $X$-axis represented the horizontal cyclic displacement $\delta$ on the top of the column. It can be observed from the figure that after installing the bucklingrestrained energy dissipation wall plates, the local buckling deformation of the specimen decreased, and the specimen exhibited better seismic performance. When weld failure or fracture of the wall plate occurred, the seismic performance of the specimen deteriorated rapidly. The smaller the axial compression ratio, the better the hysteretic performance of the novel steel box pier can be improved with the smaller ratio of the axial compression. The seismic performance of novel box steel bridge piers is greatly influenced by the axial compression ratio. 


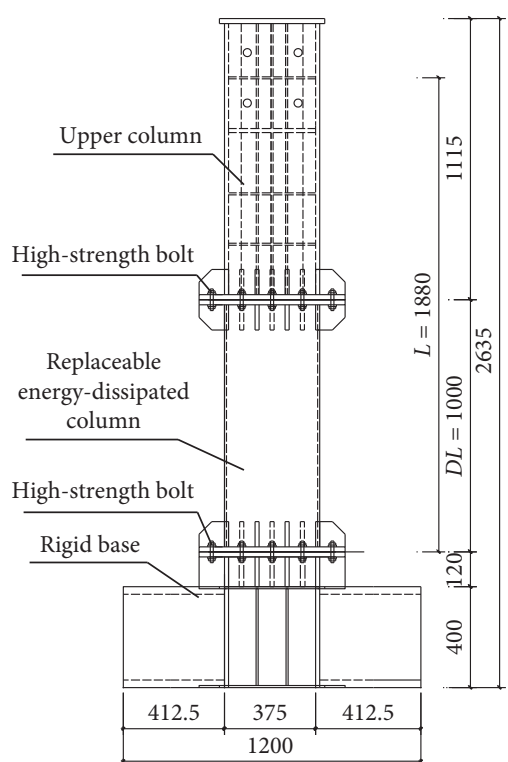

(a)

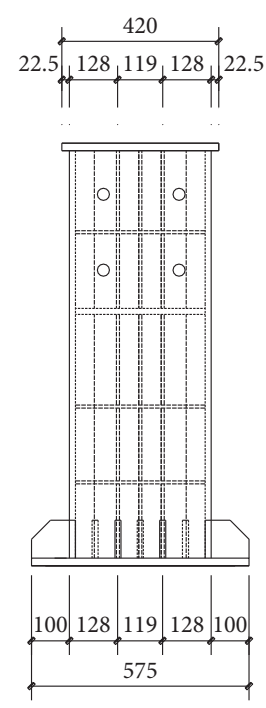

(b)

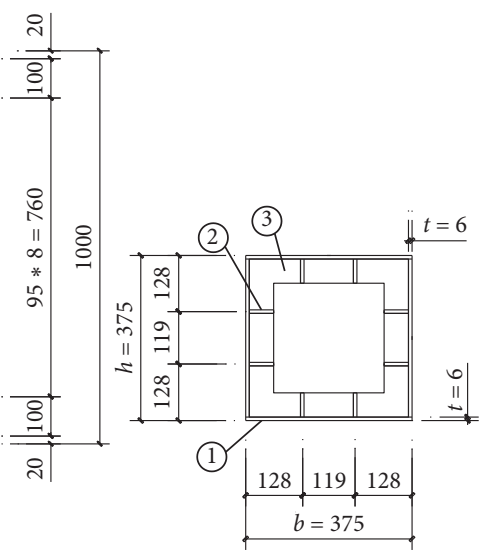

(c)

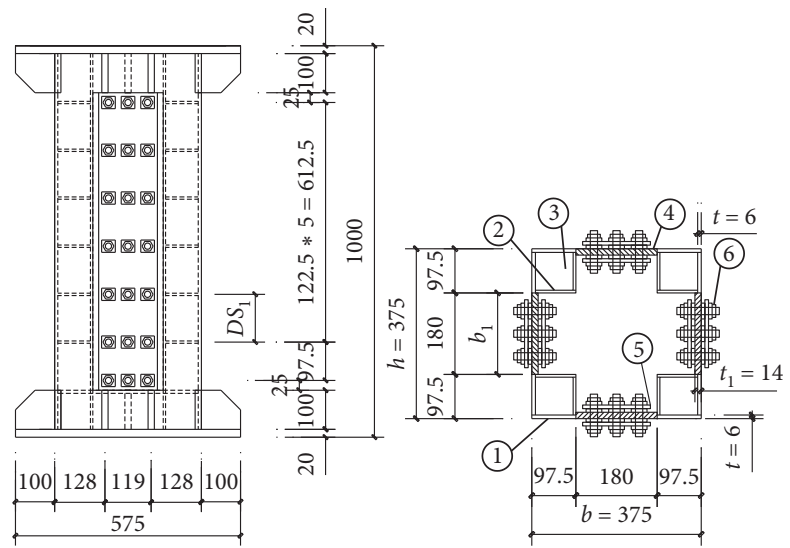

(d)

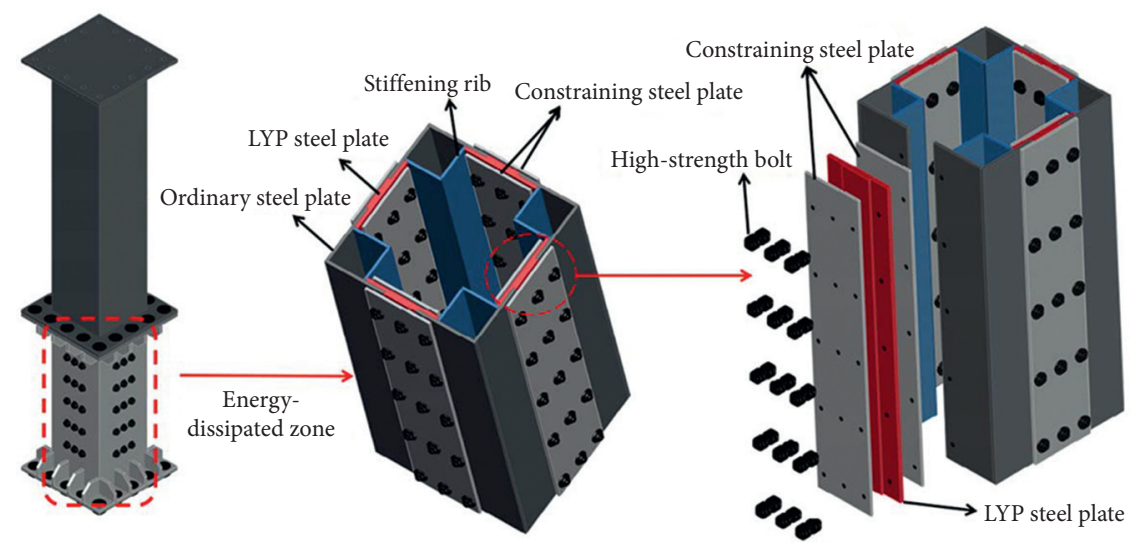

(e)

Figure 1: Design drawing of pseudostatic specimens. (a) Front elevation of specimens. (b) Front elevation of upper column. (c) Energydissipated column of specimens in group I. (d) Energy-dissipated column of specimens in group II and group III. (e) Model of energydissipated zone in group II and group III.

3.3. Skeleton Curve. Figure 9 shows the skeleton curve corresponding to the load-displacement hysteresis curve of the specimen. The influence of installing buckling-restrained energy dissipation wall plates, axial compression ratio $n$, and eccentricity $e$ on the skeleton curve was compared and analyzed. According to Figure 9(a), after installing the 
TABLE 1: The design parameters of pseudostatic specimens.

\begin{tabular}{|c|c|c|c|c|c|c|c|c|}
\hline Label of test specimens & $L(\mathrm{~mm})$ & $D L(\mathrm{~mm})$ & $b(h)(\mathrm{mm})$ & $t(\mathrm{~mm})$ & $D S_{1}(\mathrm{~mm})$ & $t_{1}(\mathrm{~mm})$ & $e(\mathrm{~mm})$ & $n$ \\
\hline I-1 & 1880 & 1000 & 375 & 6 & 95 & 0 & 0 & 0.2 \\
\hline II-1 & 1880 & 1000 & 375 & 6 & 122.5 & 14 & 0 & 0.2 \\
\hline II-2 & 1880 & 1000 & 375 & 6 & 122.5 & 14 & 0 & 0.15 \\
\hline II-3 & 1880 & 1000 & 375 & 6 & 122.5 & 14 & 0 & 0.1 \\
\hline III-1 & 1880 & 1000 & 375 & 6 & 122.5 & 14 & 80 & 0.2 \\
\hline III-2 & 1880 & 1000 & 375 & 6 & 122.5 & 14 & 80 & 0.15 \\
\hline III-3 & 1880 & 1000 & 375 & 6 & 122.5 & 14 & 80 & 0.1 \\
\hline
\end{tabular}

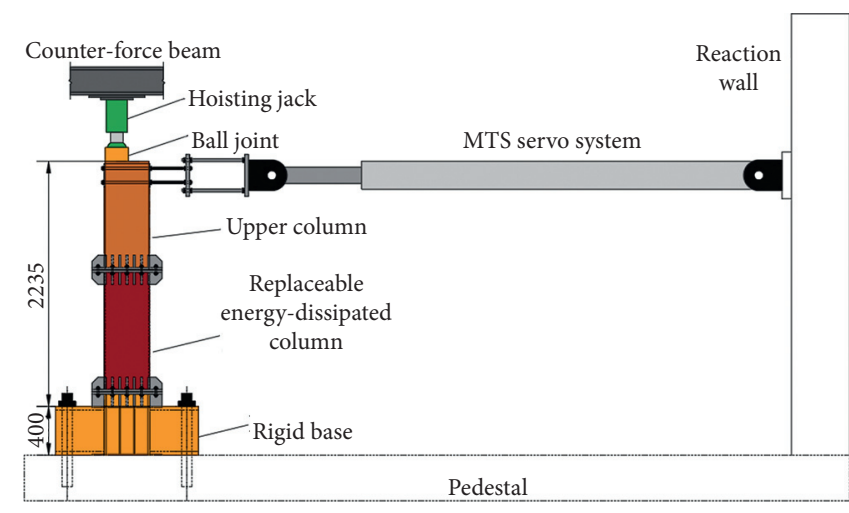

(a)

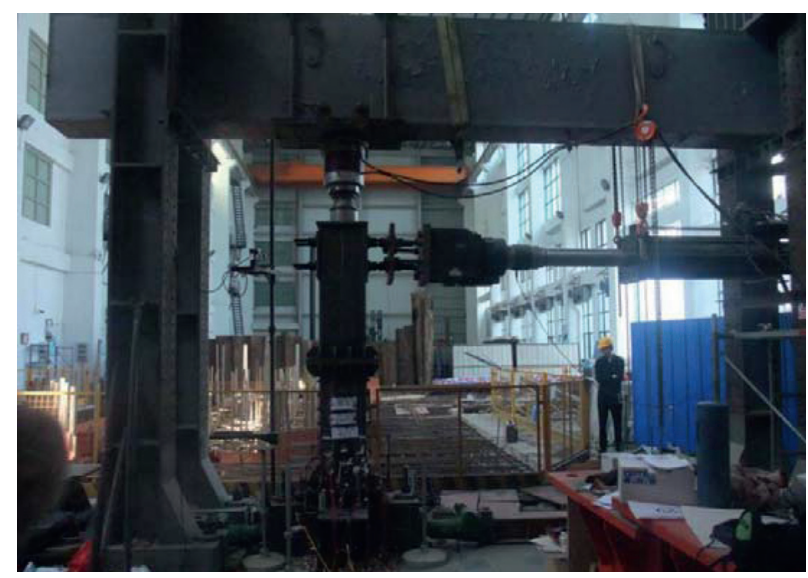

(b)

FIgUre 2: Loading system and photo of onsite loading. (a) Design of the loading system (unit: mm). (b) Photo of onsite loading.

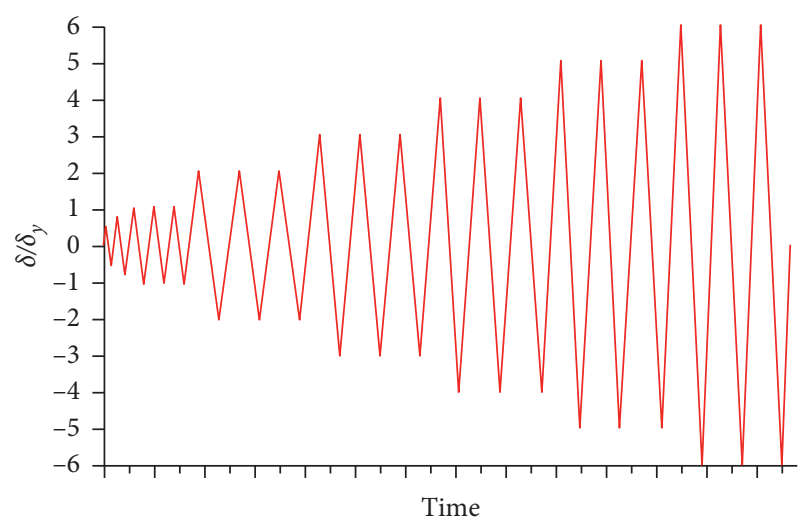

FIGURE 3: Horizontal loading scheme on the column top.

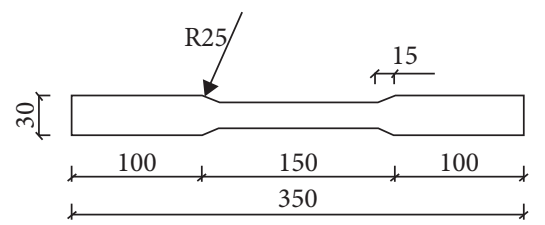

Figure 4: Design specification of the material specimen.

buckling-restrained energy dissipation wall plates, the ultimate bearing capacity of specimen has been increased by $25.5 \%$, and the ultimate displacement has been increased by $12.03 \%$. The strength and stiffness degradation of specimen occurred more slowly at the later loading stages. Figure 9(b)

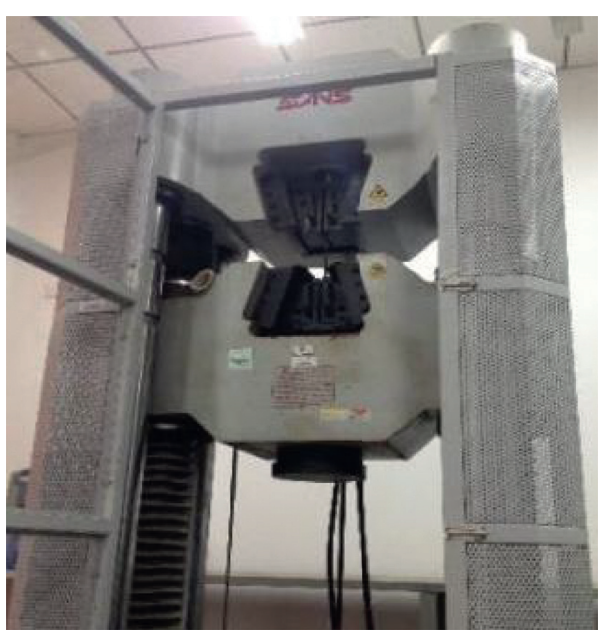

FIGURE 5: Loading equipment for the material test.

shows the specimens under axial compression, i.e., $e=0 \mathrm{~mm}$. The descending axial compression ratio gradually improved the bearing capacity of the steel bridge pier and decreased speed of the stiffness and strength degradation of specimen. When the axial compression ratio decreased from 0.2 to 0.1 , the load capacity of specimen increased by $5.68 \%$. In Figure 9(c), under a larger axial compression ratio, the influence of eccentricity on the bearing capacity, strength degradation, and stiffness degradation of the new box-type steel pier is relatively small and the maximum difference in 


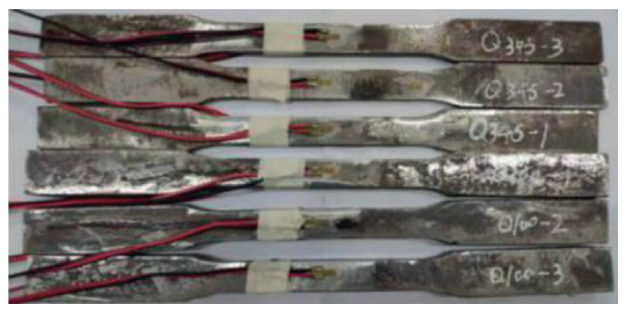

(a)

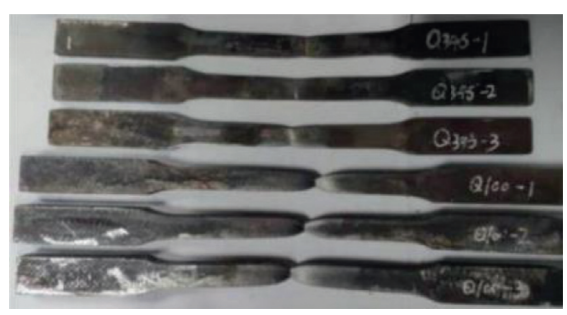

(b)

Figure 6: Photographs of the material specimens. (a) Before stretching. (b) After fracture.

TABLE 2: Test results of steel material specimens.

\begin{tabular}{|c|c|c|c|c|c|}
\hline \multicolumn{2}{|c|}{ Label of material specimens } & \multirow{2}{*}{$\begin{array}{c}\text { Thickness }(\mathrm{mm}) \\
5.8\end{array}$} & Yield strength $(\mathrm{MPa})$ & Tensile strength $(\mathrm{MPa})$ & Rate of elongation (\%) \\
\hline \multirow{4}{*}{ Q345 6 mm } & $6-1$ & & 400 & 615 & 14 \\
\hline & $6-2$ & 5.7 & 412 & 620 & 13 \\
\hline & $6-3$ & 5.8 & 388 & 603 & 14 \\
\hline & Average & 5.8 & 400 & 613 & 13.7 \\
\hline \multirow{4}{*}{ LYP100 14 mm } & $14-1$ & 14.5 & 138 & 260 & 31 \\
\hline & $14-2$ & 14.6 & 137 & 267 & 33 \\
\hline & $14-3$ & 14.7 & 140 & 266 & 36 \\
\hline & Average & 14.6 & 138 & 264 & 33.3 \\
\hline
\end{tabular}

ultimate bearing capacity of specimens with different eccentricity is only $0.53 \%$.

3.4. Bearing Capacity and Deformation Capacity. Nominal yield point, peak point, deformation at the extreme point, and horizontal force at the column top were summarized as in Table 3. The nominal yield point is the point on the skeleton curve corresponding to the theoretical value of $\delta_{\mathrm{y}}$. The peak point is the point corresponding to the maximum horizontal load on the skeleton curve. According to the provision of Article 4.4.4 of Specification for Seismic Test of Buildings (JGJ/T 101-2015) [29], the extreme point was taken as the point on the skeleton curve corresponding to the reduction of horizontal load on the column top to $85 \%$ of the peak point. The parameters $V$ and $\delta$ represent the horizontal force and horizontal displacement of the column top, respectively. The subscripts of parameters $V$ and $\delta$ indicate the points under calculation. For example, $V_{\max }$ represents the horizontal force on the column top at the peak point. In Table 3, $L$ means the specimen height under calculation in the pseudostatic test, equal to $1880 \mathrm{~mm}$.

By comparing specimen I-1 and II-1, it could be found that after installing the energy dissipation wall plates, the bearing capacity of the steel box bridge pier increased significantly. The value of $V_{\mathrm{y}} / V_{\max }$ lies within the range of 0.79-0.92 for each specimen in the pseudostatic test. A comparison with the specimens in group II indicated that the axial compression ratio had lesser impact on the horizontal force $V_{\mathrm{y}}$ on the column top at the nominal yield point and horizontal force $V_{\max }$ of the column top at the peak point in axially compressed specimens of the pseudostatic test. Comparison with the group III specimens indicated that, as the axial compression ratio decreased, the horizontal force $V_{\mathrm{y}}$ on the column top at the nominal yield point and horizontal force $V_{\max }$ on the column top at the peak point gradually increased in eccentrically compressed specimens of the pseudostatic test.

After installing the energy dissipation wall plates, the horizontal displacement $\delta_{\max }$ of the column top at the peak point and horizontal displacement $\delta_{\mathrm{u}}$ of the column top at the extreme point increased by $41 \%$ and $24 \%$, respectively. As the axial compression ratio increased, the ductility coefficient of the specimen and the capacity of deformation were improved. When the axial compression ratio $n$ equals 0.20 , that is, $n=0.20$, the ductility coefficient increased due to the eccentricity, to approximately $10.4 \%$; when the axial compression ratio $n$ was equal to 0.15 , the ductility coefficient decreased due to the eccentricity, to approximately $35.5 \%$; when the axial compression ratio was $n=0.10$, the ductility coefficient increased due to the eccentricity, to approximately $11.7 \%$.

3.5. Stiffness Degradation. Equation (1) was used to calculate the secant stiffness $K_{\mathrm{j}}$ of the specimens in the pseudostatic test, so as to describe the degree of stiffness degradation of the specimen:

$$
K_{j}=\frac{\left|+V_{j}\right|+\left|-V_{j}\right|}{\left|\delta_{j}\right|+\left|-\delta_{j}\right|}
$$

where $V_{j}$ means the peak load on the column top under $j$-th loading level in the horizontal direction; $\delta_{j}$ means the horizontal displacement on the top of the column which corresponding to the peak horizontal load under $j$-th loading level. Figure 10 shows the variation of secant stiffness during the pseudostatic test. In Figure 10, the $Y$-axis represents the ratio of secant stiffness $K_{j}$ to the secant stiffness $K_{\mathrm{y}}$ under $j$-th loading level; the $X$-axis represents the ratio of displacement 


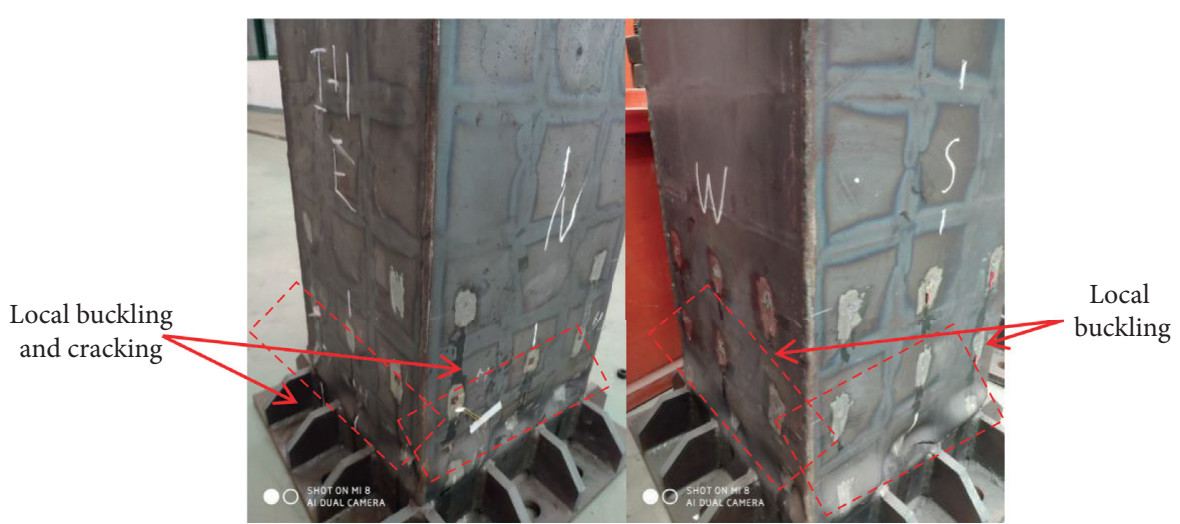

(a)

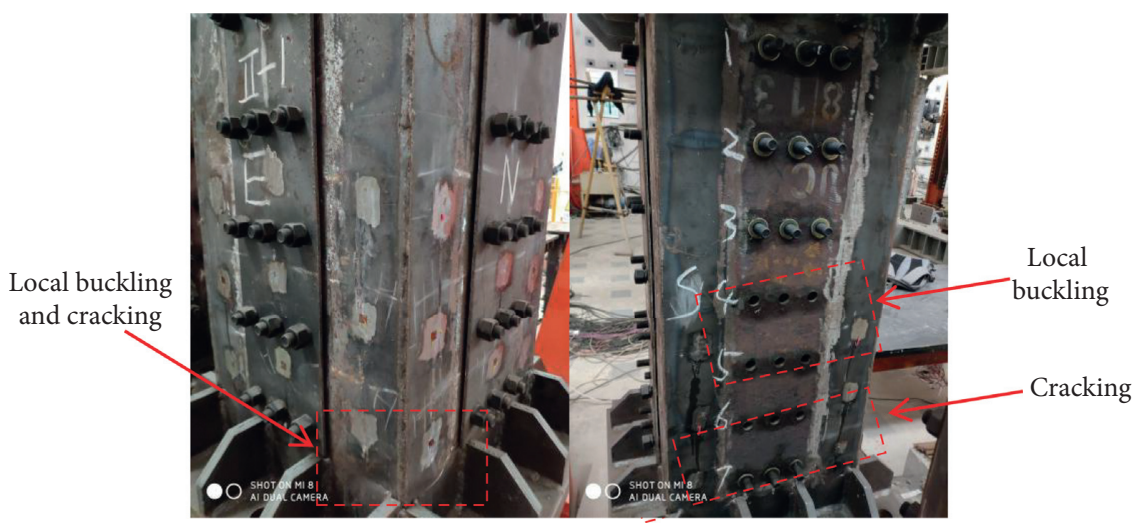

(b)

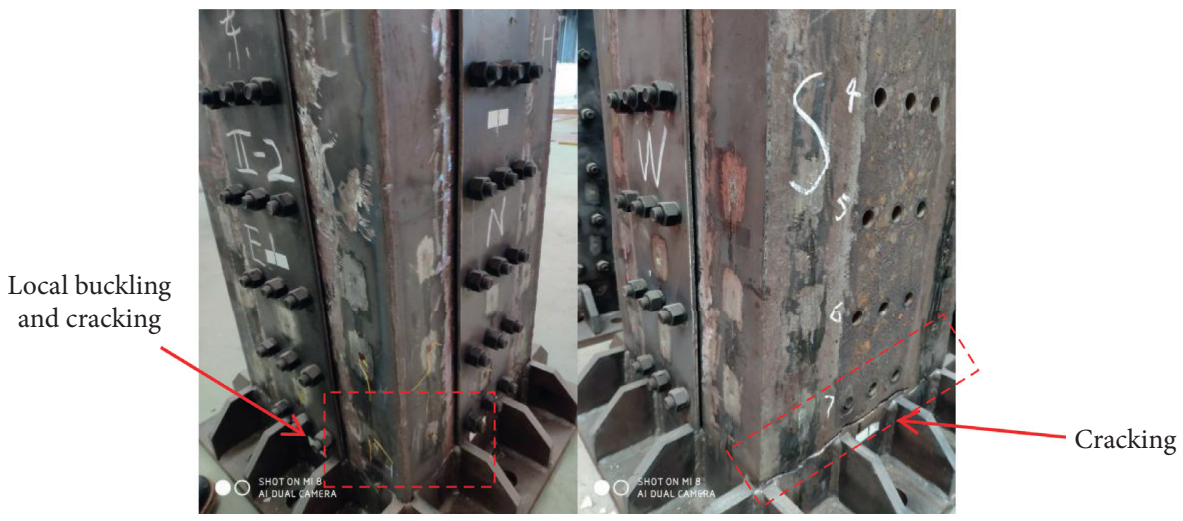

(c)

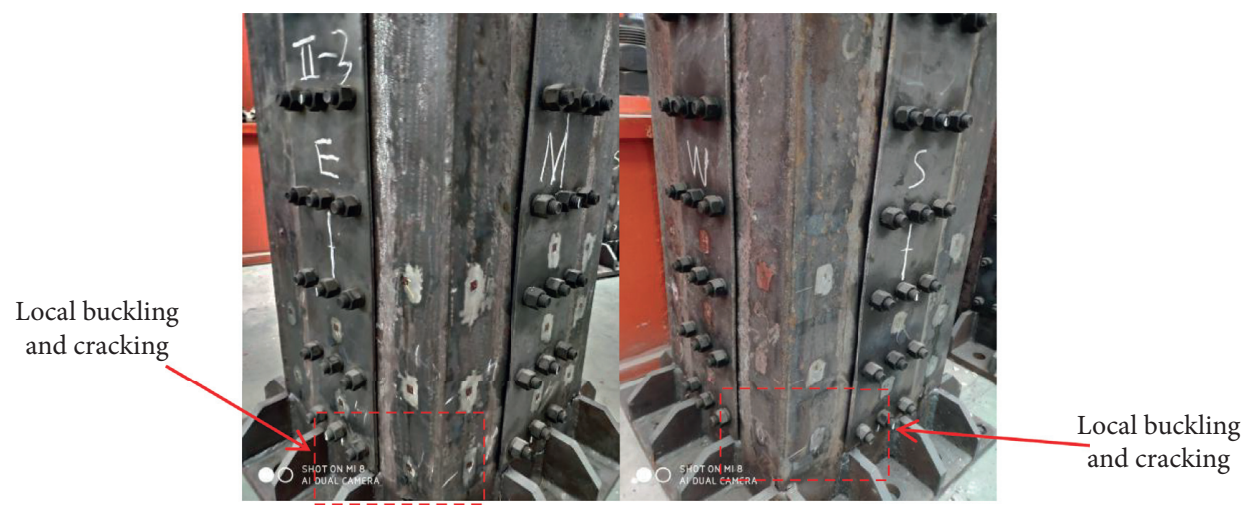

(d)

Figure 7: Continued. 


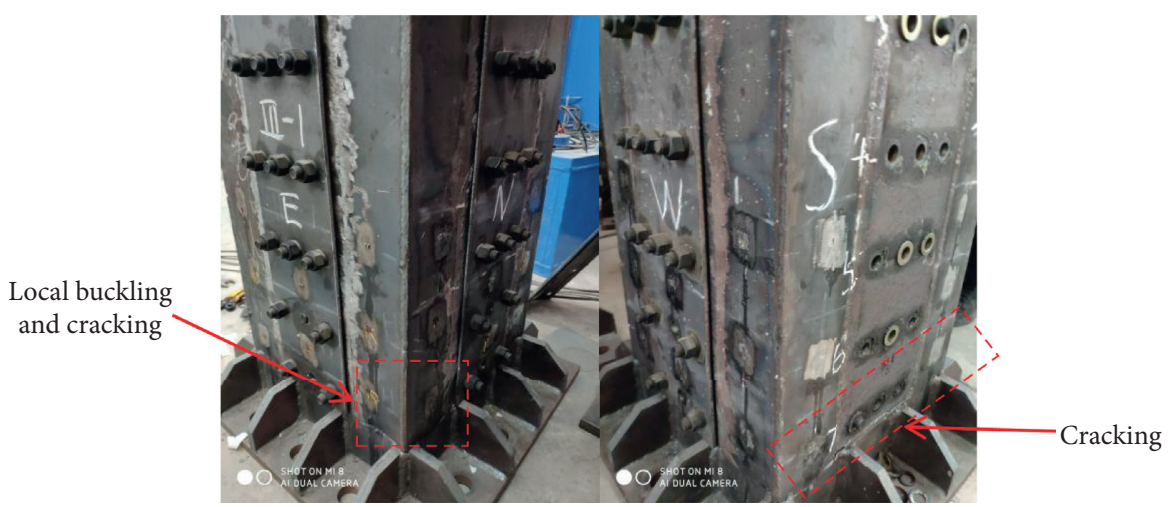

(e)

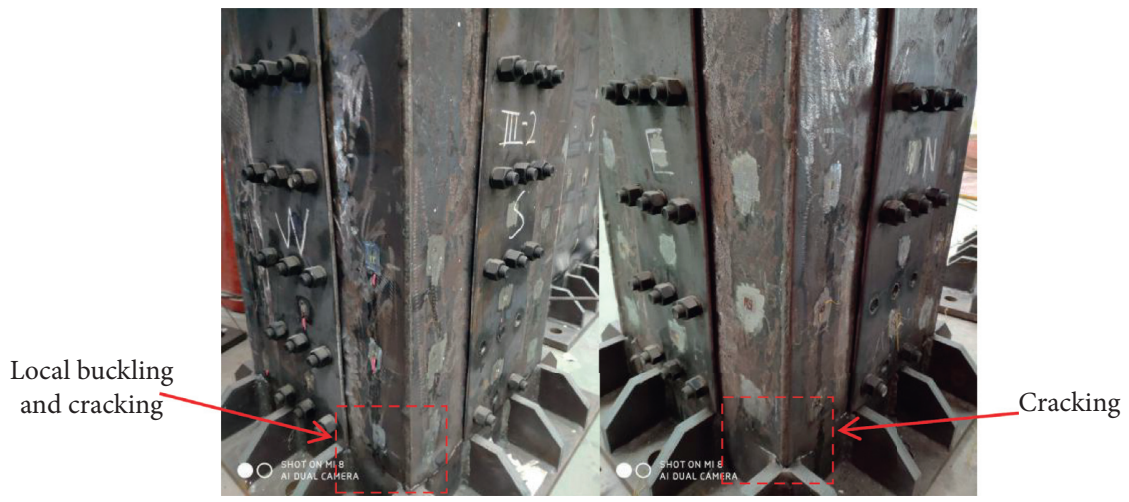

(f)

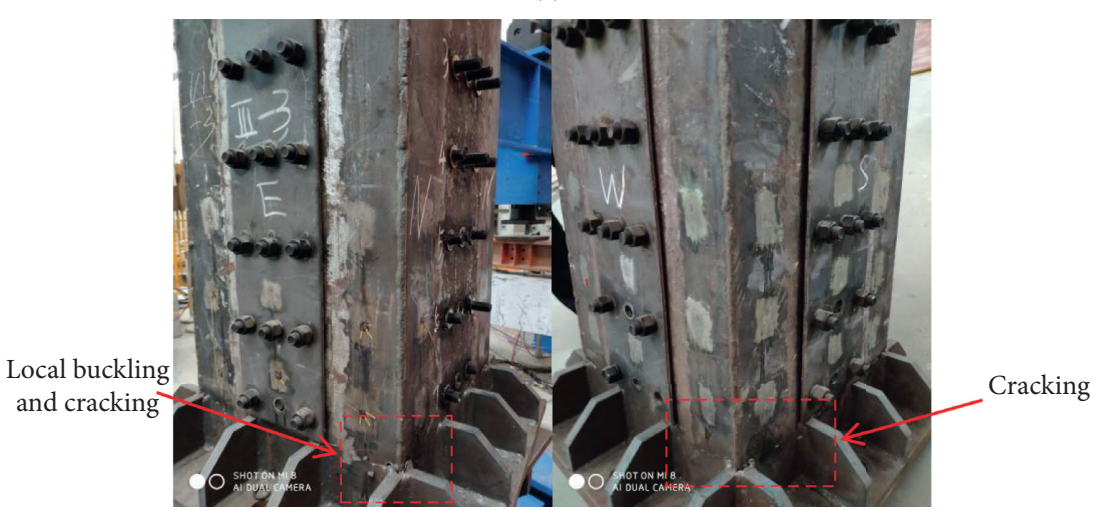

(g)

Figure 7: Failure modes of pseudostatic specimens. (a) Specimen I-1. (b) Specimen II-1. (c) Specimen II-2. (d) Specimen II-3. (e) Specimen III-1. (f) Specimen III-2. (g) Specimen III-3.

$\delta$ under loading to the theoretical yield displacement $\delta_{\mathrm{y}}$. As shown in Figure 10, at the early stage of loading, the slope of the stiffness degradation curve of the specimen varied little; but at a later stage, with the installation of the energy dissipation wall plate, the slope of the stiffness degradation curve of the specimen decreased, indicating that the stiffness degradation slowed down. The stiffness degradation of the specimens in the pseudostatic test is slightly influenced by the axial compression ratio and eccentricity of specimen.

3.6. Strength Degradation. Equation (2) was used to calculate the strength degradation coefficient $\lambda_{j}$ of the specimen, so as to describe the degree of strength degradation of the specimen in the pseudostatic test:

$$
\lambda_{j}=\frac{V_{j}^{i}}{V_{j}^{1}},
$$

where $V_{j}^{i}$ is the peak load on the column top under the $i$-th cycle of the $j$-th loading level in horizontal direction; $V_{j}^{1}$ is the peak load on the column top under the first cycle of the $j$-th loading level in horizontal direction. Figure 11 shows the variation of the strength degradation coefficient $\lambda_{j}$ of the specimen in the pseudostatic test. As seen from Figure 11, after installing the energy dissipation wall plates, strength degradation of the specimen was delayed, and the slope of the strength degradation coefficient curve decreased at the later loading stage, indicating that the strength degradation of the specimen slowed down. When the axial compression ratio $n$ 


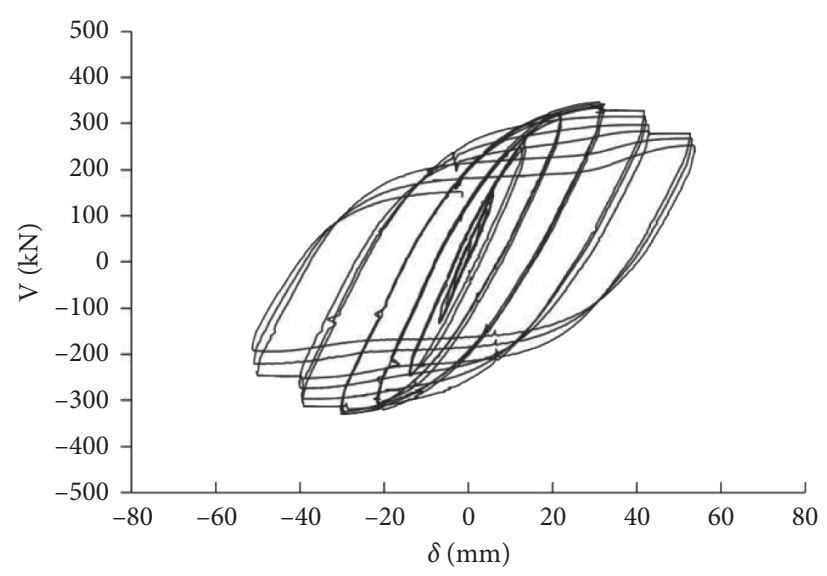

(a)

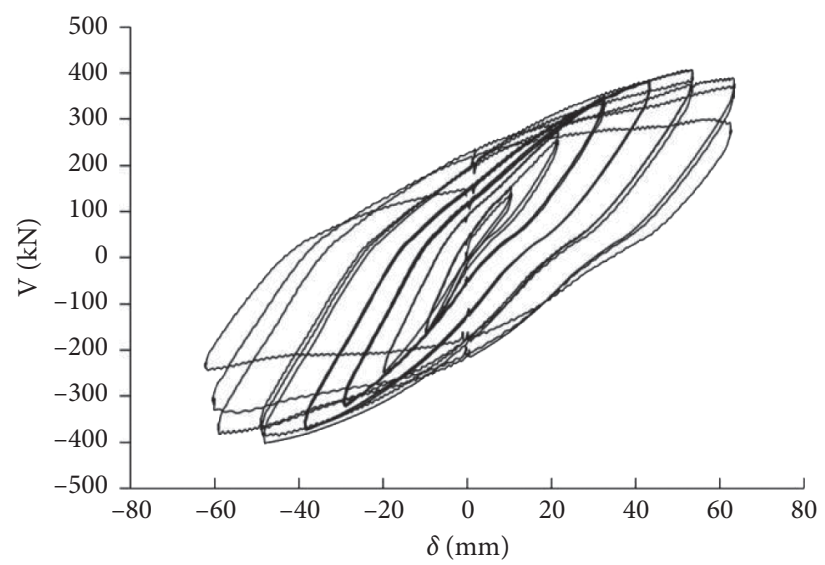

(c)

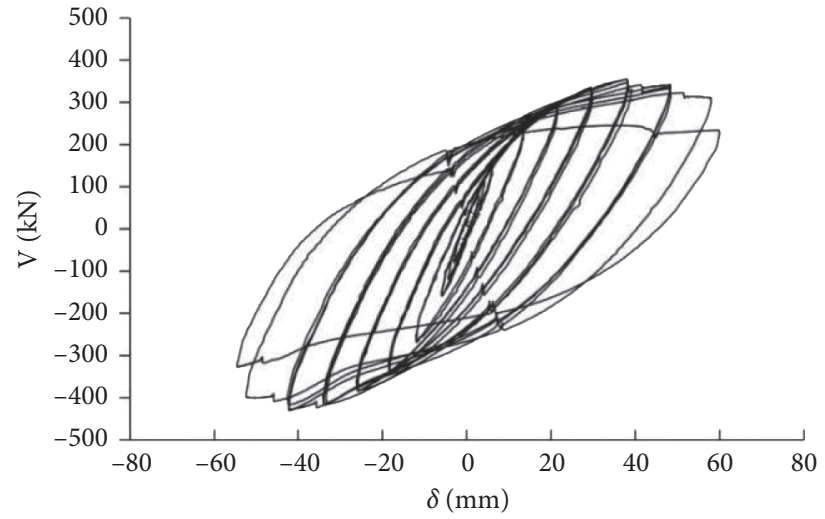

(e)

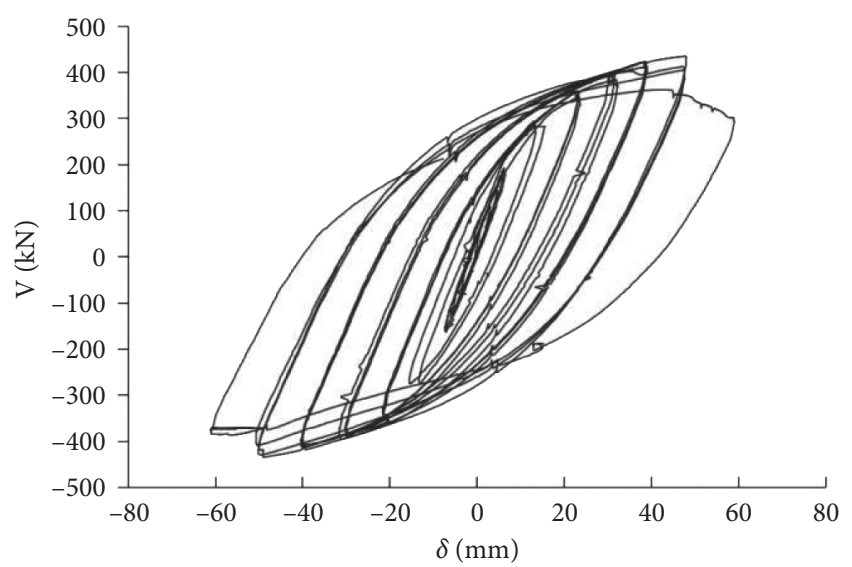

(b)

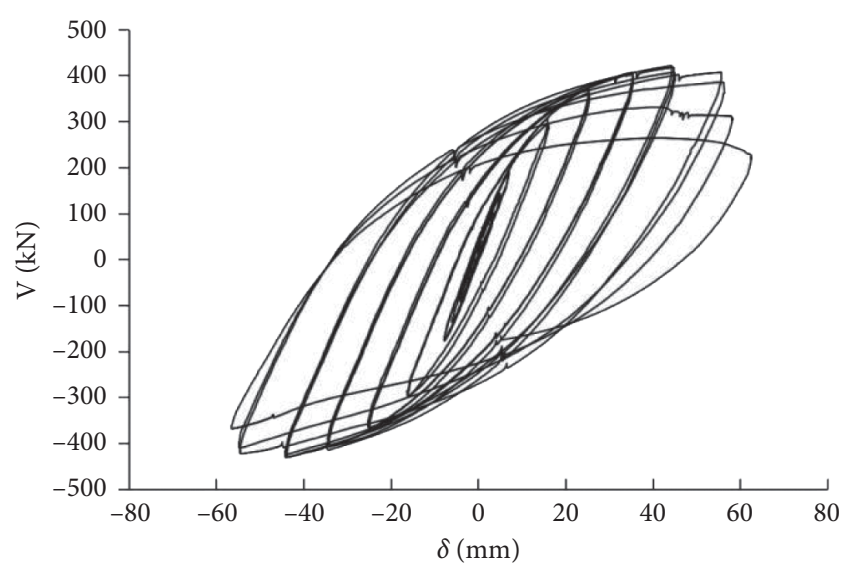

(d)

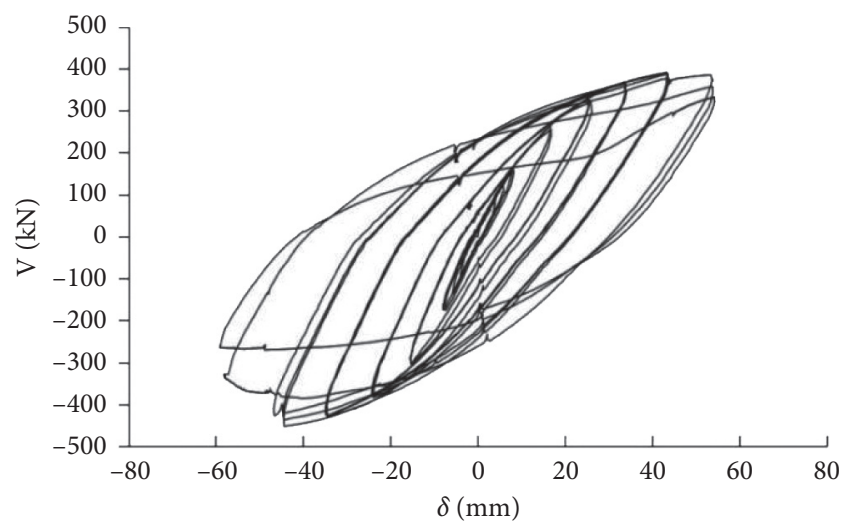

(f)

Figure 8: Continued. 


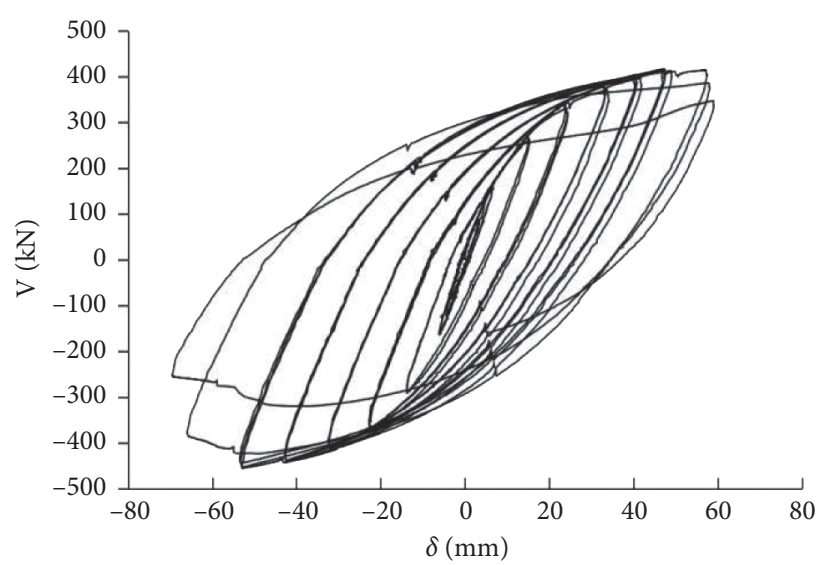

(g)

FIgURE 8: Load-displacement hysteresis curves of the specimens. (a) Specimen I-1 $(n=0.20, e=0 \mathrm{~mm})$. (b) Specimen II-1 $(n=0.20$, $e=0 \mathrm{~mm})$. (c) Specimen II-2 $(n=0.15, e=0 \mathrm{~mm})$. (d) Specimen II-3 $(n=0.10, e=0 \mathrm{~mm})$. (e) Specimen III-1 $(n=0.20, e=80 \mathrm{~mm})$. (f) Specimen III-2 $(n=0.15, e=80 \mathrm{~mm})$. (g) Specimen III-3 $(n=0.10, e=80 \mathrm{~mm})$.

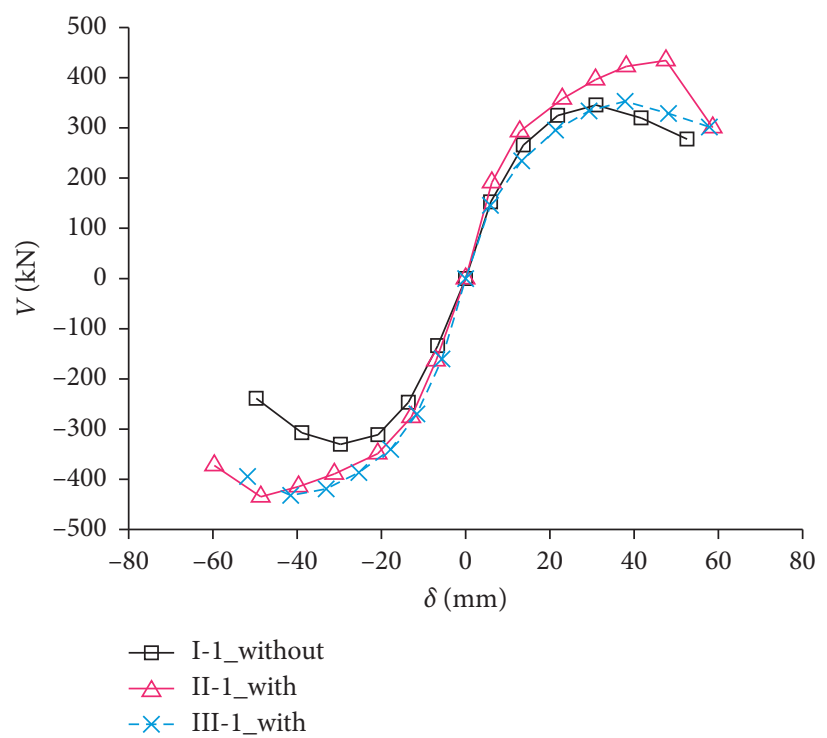

(a)
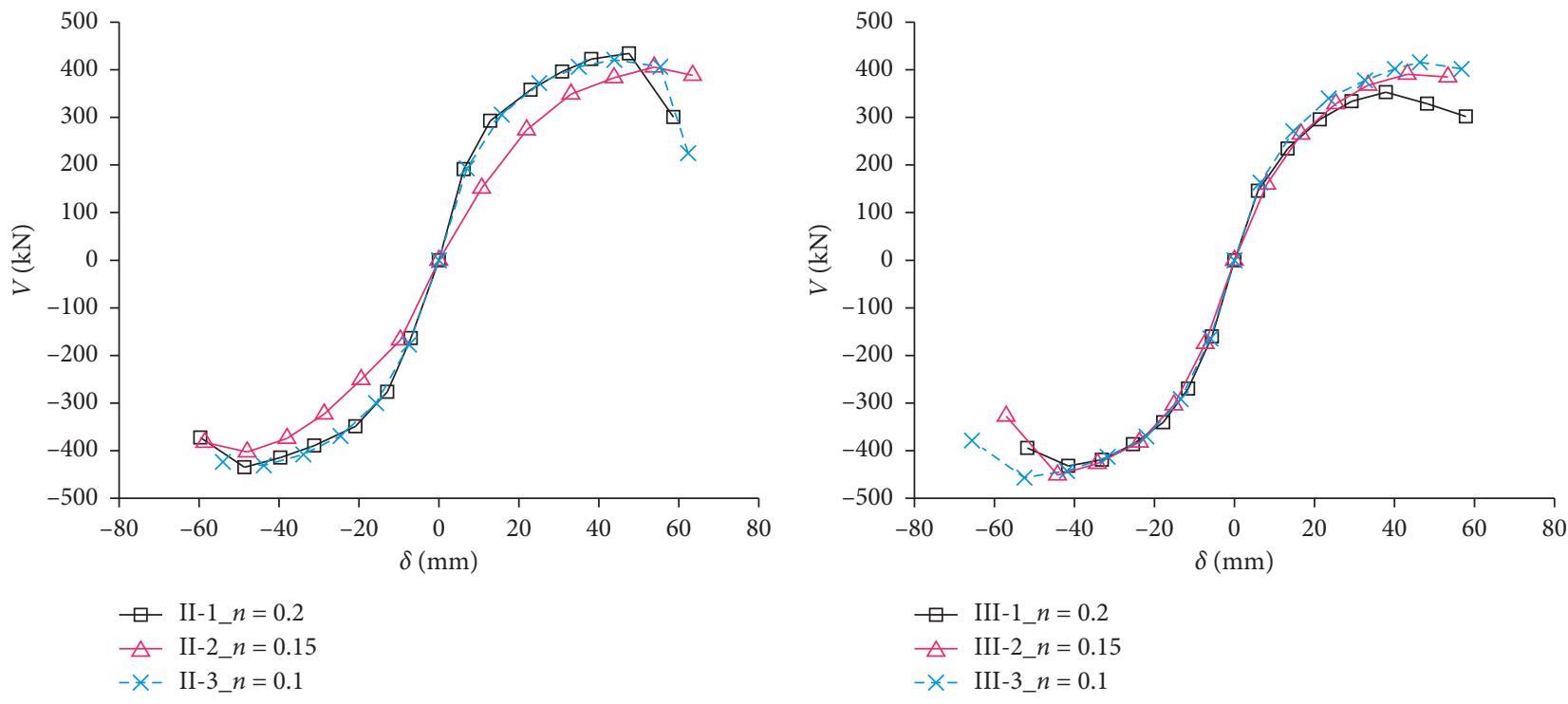

(i) $e=0 \mathrm{~mm}$

(ii) $e=80 \mathrm{~mm}$

(b)

Figure 9: Continued. 


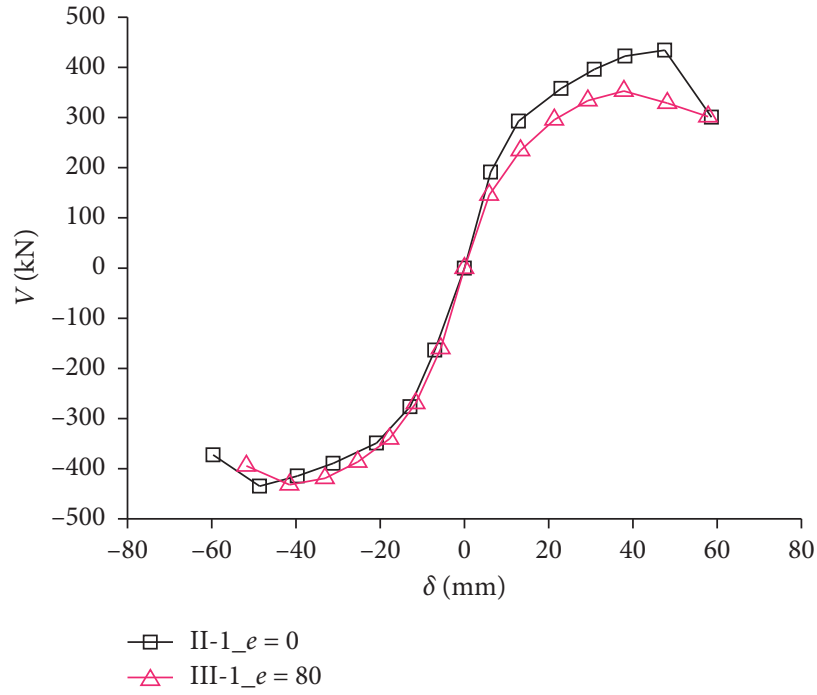

(i) $n=0.20$

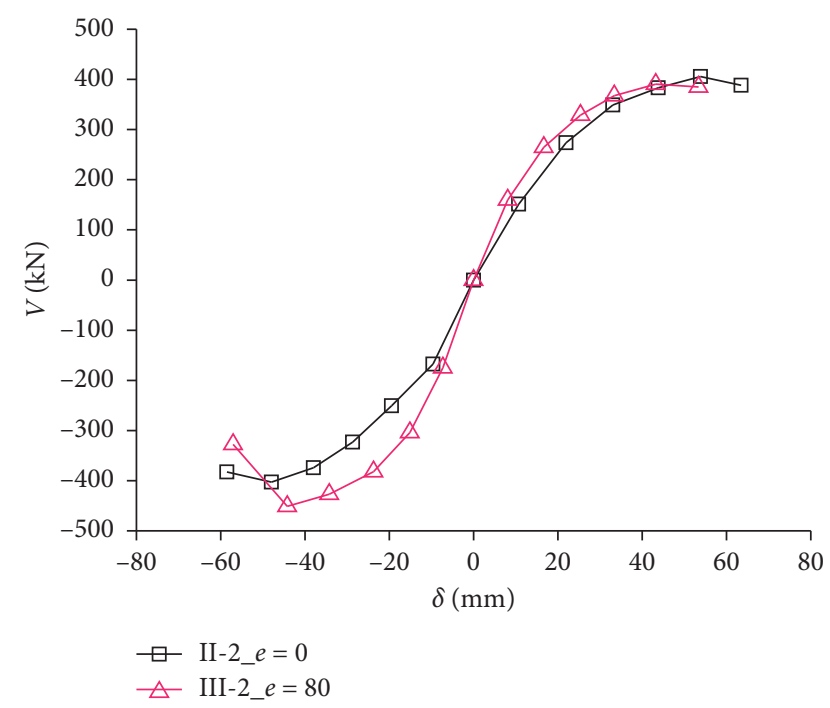

(ii) $n=0.15$

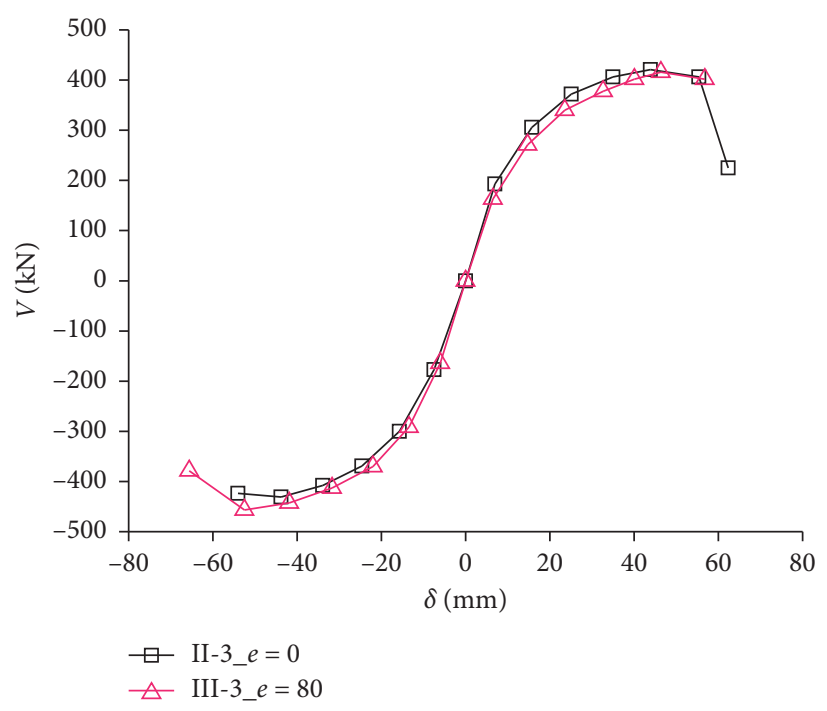

(iii) $n=0.10$

(c)

FiguRE 9: Skeleton curves of the specimens. (a) Effects of installing buckling-restrained energy dissipation wall plates. (b) Effects of axial compression ratio $n$. (c) Effects of eccentricity $e$.

TABLE 3: Results about loading bearing and deformation of pseudostatic specimens.

\begin{tabular}{|c|c|c|c|c|c|c|c|c|c|c|c|}
\hline \multirow{2}{*}{\multicolumn{2}{|c|}{$\begin{array}{l}\text { Specimen } \\
\text { label }\end{array}$}} & \multicolumn{3}{|c|}{ Nominal yield point } & \multicolumn{3}{|c|}{ Peak point } & \multicolumn{2}{|c|}{ Extreme point } & \multirow{2}{*}{$V_{\mathrm{y}} / V_{\max }$} & \multirow{2}{*}{ Ductility $\mu=\delta_{\mathrm{u}} / \delta_{\mathrm{y}}$} \\
\hline & & $\delta_{\mathrm{y}}(\mathrm{mm})$ & $V_{\mathrm{y}}(\mathrm{kN})$ & $\theta_{\mathrm{y}}=\delta_{\mathrm{y}} / L$ & $\delta_{\max }(\mathrm{mm})$ & $V_{\max }(\mathrm{kN})$ & $\theta_{\max }=\delta_{\max } / L$ & $\delta_{\mathrm{u}}(\mathrm{mm})$ & $\theta_{\mathrm{u}}=\delta_{\mathrm{u}} / L$ & & \\
\hline \multirow{2}{*}{ I- 1} & Plus & 9.5 & 295.04 & $1 / 198$ & 30.99 & 345.72 & $1 / 61$ & 48.40 & $-1 / 39$ & 0.85 & 5.09 \\
\hline & Minus & -9.5 & -303.31 & $-1 / 198$ & -29.71 & -330.45 & $-1 / 63$ & -43.08 & $-1 / 44$ & 0.92 & 4.53 \\
\hline \multirow{2}{*}{ II-1 } & Plus & 9.5 & 341.32 & $1 / 198$ & 47.58 & 434.29 & $1 / 40$ & 52.99 & $1 / 35$ & 0.79 & 5.58 \\
\hline & Minus & -9.5 & -383.17 & $-1 / 198$ & -48.64 & -434.99 & $-1 / 39$ & -60.19 & $-1 / 31$ & 0.88 & 6.34 \\
\hline \multirow{2}{*}{ II-2 } & Plus & 10.1 & 359.83 & $1 / 186$ & 53.84 & 405.65 & $1 / 35$ & 63.48 & $1 / 30$ & 0.89 & 6.29 \\
\hline & Minus & -10.1 & -348.60 & $-1 / 186$ & -47.98 & -403.00 & $-1 / 39$ & -58.53 & $-1 / 32$ & 0.87 & 5.80 \\
\hline \multirow{2}{*}{ II-3 } & Plus & 10.8 & 345.71 & $1 / 174$ & 43.91 & 420.86 & $1 / 43$ & 57.25 & $1 / 33$ & 0.82 & 5.30 \\
\hline & Minus & -10.8 & -369.48 & $-1 / 174$ & -43.81 & -431.15 & $-1 / 43$ & -54.07 & $-1 / 35$ & 0.86 & 5.01 \\
\hline \multirow{2}{*}{ III-1 } & Plus & 9.5 & 292.23 & $1 / 198$ & 37.83 & 353.08 & $1 / 50$ & 58.49 & $1 / 32$ & 0.83 & 6.16 \\
\hline & Minus & -9.5 & -360.42 & $-1 / 198$ & -41.56 & -432.07 & $-1 / 45$ & -59.21 & $-1 / 32$ & 0.83 & 6.23 \\
\hline \multirow{2}{*}{ III-2 } & Plus & 10.1 & 336.36 & $1 / 186$ & 43.18 & 390.55 & $1 / 44$ & 53.39 & $1 / 35$ & 0.86 & 5.29 \\
\hline & Minus & -10.1 & -387.94 & $-1 / 186$ & -44.23 & -451.40 & $-1 / 43$ & -51.27 & $-1 / 37$ & 0.86 & 5.08 \\
\hline \multirow{2}{*}{ III-3 } & Plus & 10.8 & 342.53 & $1 / 174$ & 46.35 & 416.04 & $1 / 41$ & 56.78 & $1 / 33$ & 0.82 & 5.26 \\
\hline & Minus & -10.8 & -377.54 & $-1 / 174$ & -52.48 & -456.65 & $-1 / 36$ & -63.98 & $-1 / 29$ & 0.83 & 5.92 \\
\hline
\end{tabular}




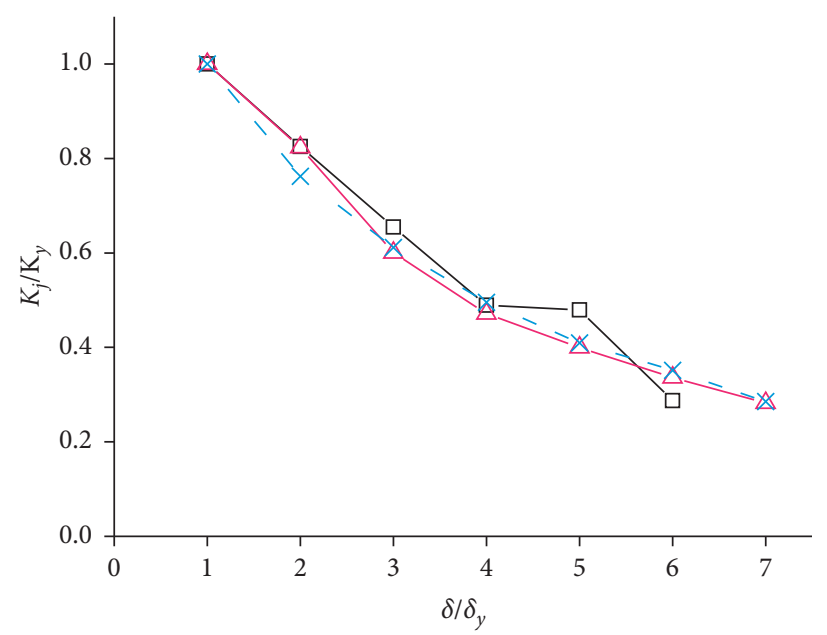

-ם- I-1_without

$-\triangle-$ II-1_with

$-X-$ III-1_with

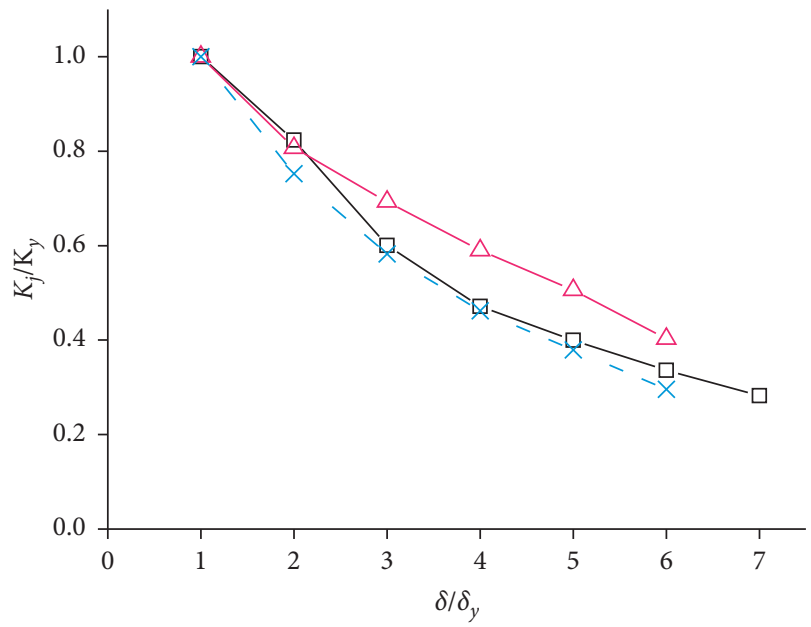

(a)

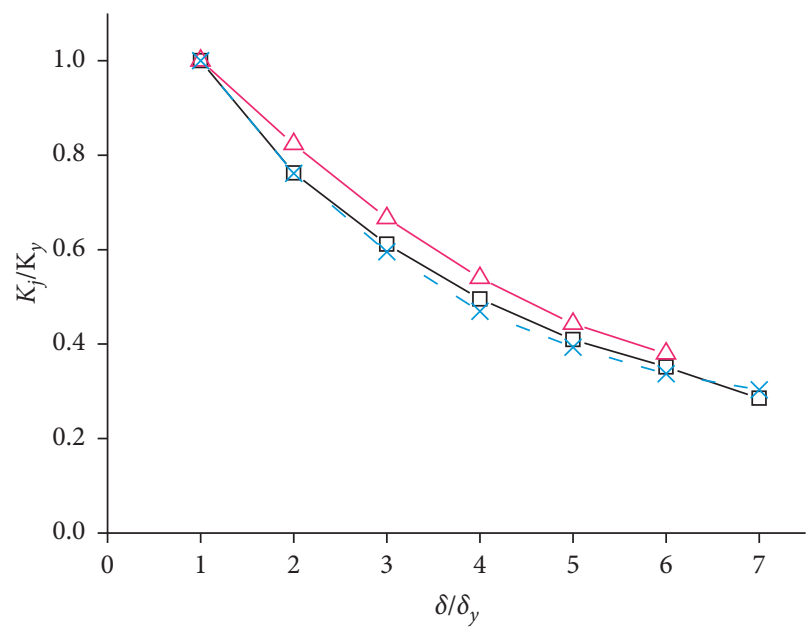

- $\square-$ II-1_n $n=0.2$

- - - III-1_n $=0.2$

$-\triangle-$ III-2_n $=0.15$

$\begin{aligned} &-\triangle- \text { II-2_n } n=0.15 \\ &-\mathrm{X}-\mathrm{II}-3 \_n=0.1\end{aligned}$

(i) $e=0 \mathrm{~mm}$

$-X$ - III-3_n $=0.1$

(ii) $e=80 \mathrm{~mm}$

(b)

Figure 10: Continued. 


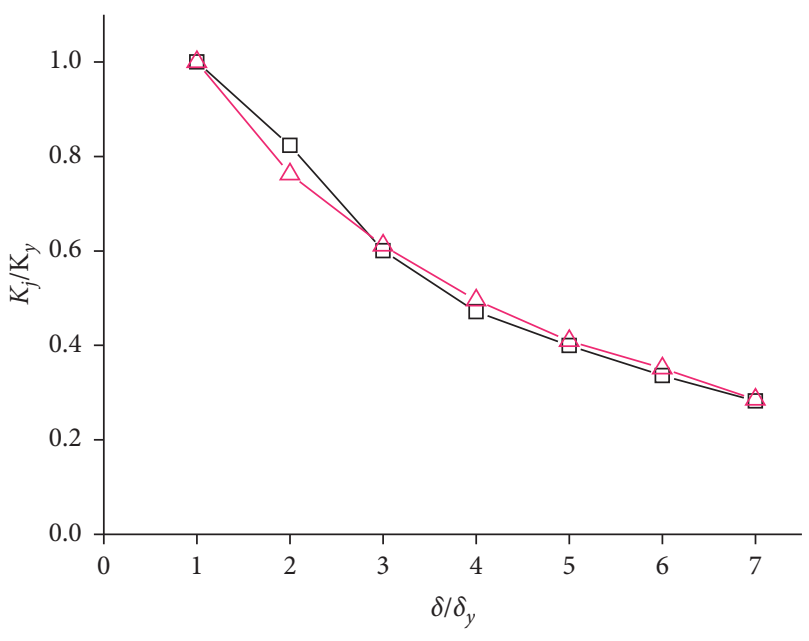

$-\square-$ II-1_e $=0$
$-\triangle-$ III-1 $e=80$

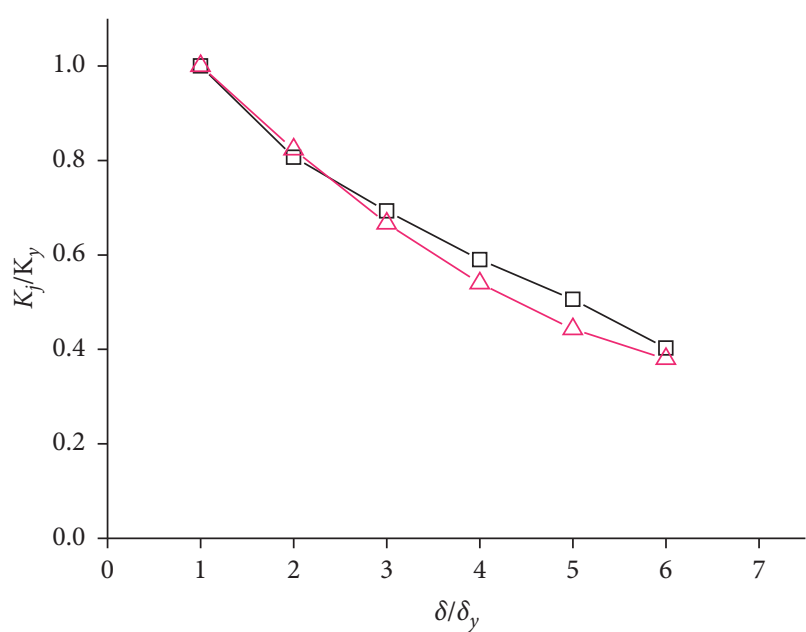

- $\square-$ II- $2 \_e=0$

$-\triangle$ III- $2 \_e=80$

(ii) $n=15$

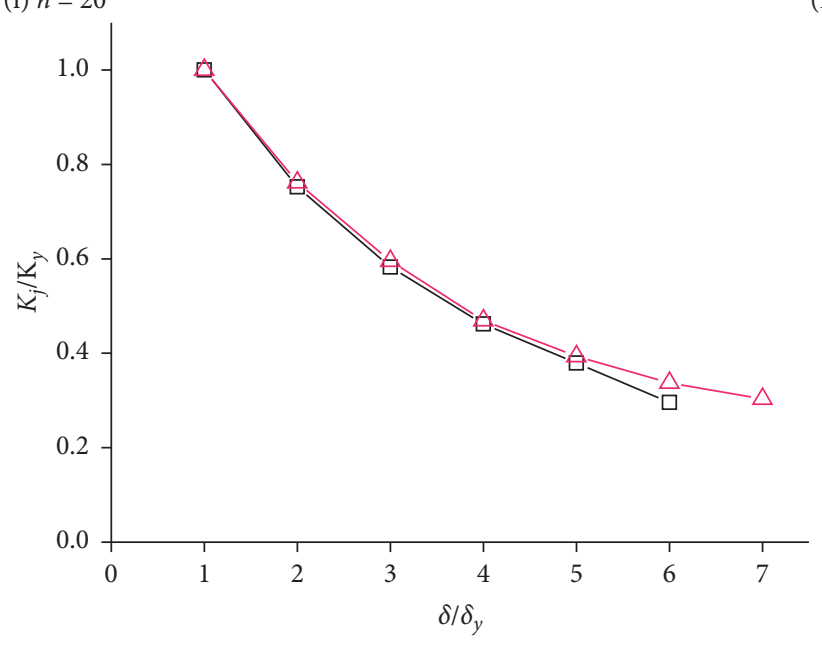

- $\square-$ II-3_e $=0$

$-\triangle-$ III-3_e $=80$

(iii) $n=10$

(c)

FiguRE 10: Degradation characteristic of stiffness. (a) Effects of installing buckling-restrained energy dissipation wall plates. (b) Effects of axial compression ratio $n$. (c) Effects of eccentricity $e$.

was equal to 0.15 , strength degradation was most conspicuous in the pseudostatic test. Moreover, such degradation phenomenon was more severe for axially compressed specimens than the eccentrically compressed specimens.

3.7. Capacity of Energy Dissipation. Equation (3) was used to obtain the equivalent viscous damping coefficient $h_{\mathrm{e}}$ of the specimen, so as to describe the specimen's capacity of energy dissipation. In the formula, $S$ means the area enclosed by the hysteresis loop; $S_{\mathrm{ABO}}$ is the area of triangle $\mathrm{ABO} ; S_{\mathrm{CDO}}$ is the area of triangle CDO. Areas of the hysteresis loop and triangle are shown in Figure 12:

$$
h_{e}=\frac{1}{2 \pi} \frac{S}{S_{\triangle \mathrm{ABO}}+S_{\triangle \mathrm{CDO}}} .
$$

Figure 13 shows the variation of the equivalent viscous damping coefficient $h_{\mathrm{e}}$ of the specimen. It can be seen that as the load level increased, the $h_{\mathrm{e}}$ gradually increased as well, indicating the improvement of the energy dissipation capacity. After installing energy dissipation wall plates, $h_{\mathrm{e}}$ increased by more than $50 \%$ at the initial loading stage, which indicated effective energy dissipation due to the plates. The value of $h_{\mathrm{e}}$ also increased upon specimen failure, indicating the improvement of energy dissipation capacity under the ultimate state. When compared with axially compressed specimens in the pseudostatic test, the energy dissipation capacity of the eccentrically compressed specimens is slightly influenced by the axial compression ratio. The eccentricity had little impact on the capacity of energy dissipation at a lower axial compression ratio. However, under a relatively larger axial compression ratio, as the 


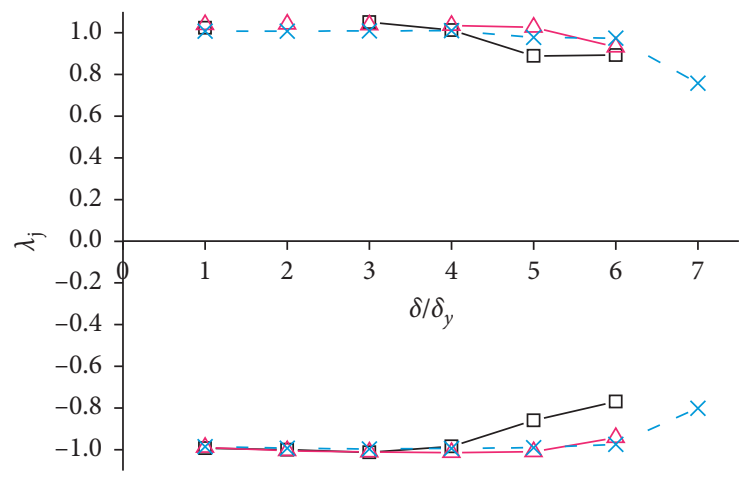

-ם- I-1_without

$-\triangle$ - II-1_with

-X- III-1_with

(a)

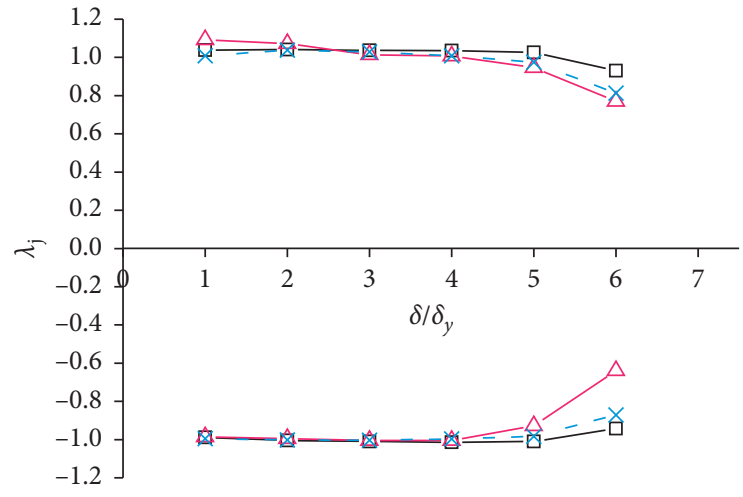

- - II- $1 \_n=0.2$

$-\triangle-$ II-2_n $=0.15$

$-X-$ II-3_n $n=0.1$

(i) $e=0 \mathrm{~mm}$

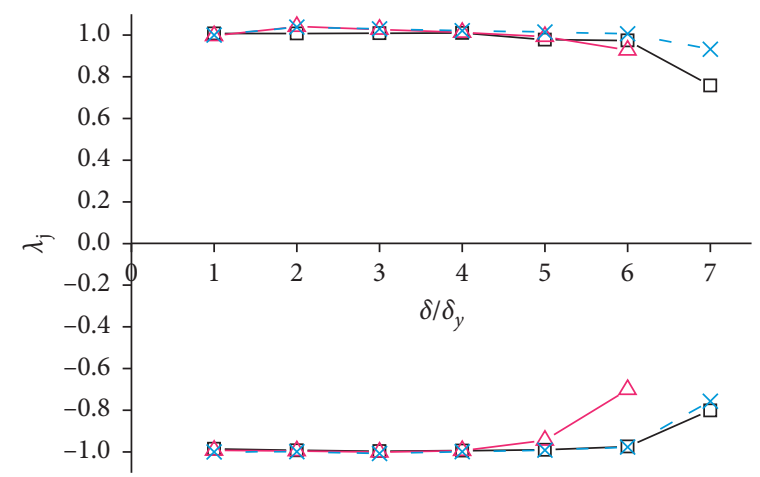

- - III-1_n $=0.2$

$-\triangle$ III-2_n $=0.15$

$-X-$ III-3_n $=0.1$

(ii) $e=80 \mathrm{~mm}$

(b)

FIgURE 11: Continued. 


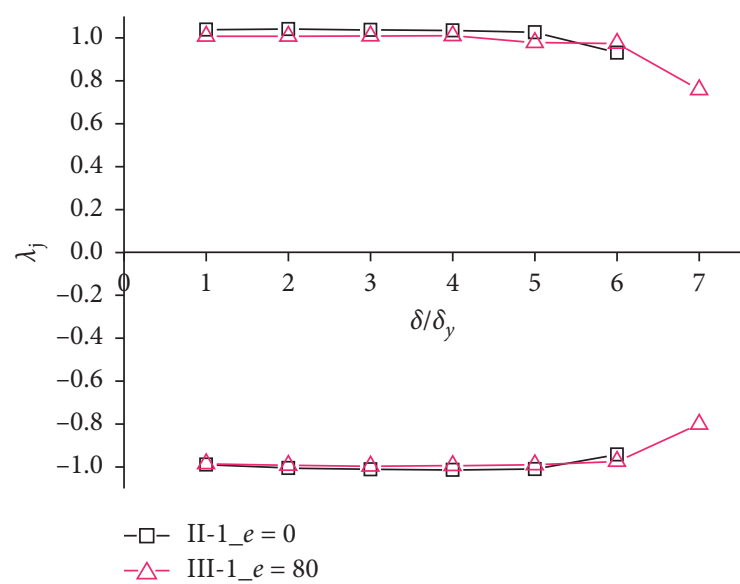

(i) $n=0.20$

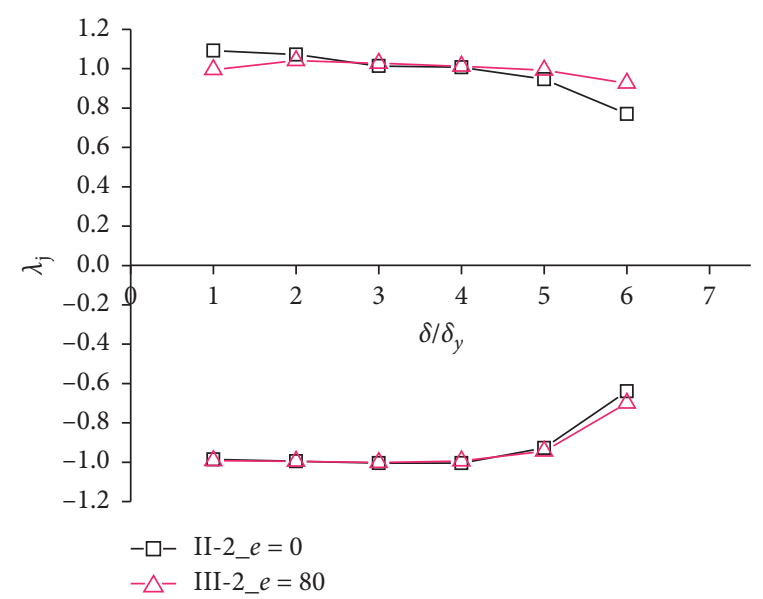

(ii) $n=0.15$

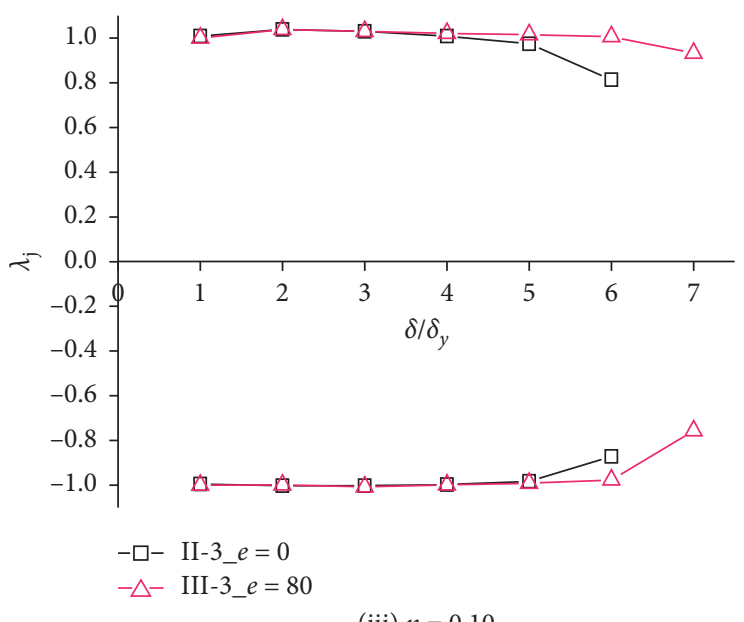

(c)

FIGURE 11: Degradation characteristic of strength. (a) Effects of installing buckling-restrained energy dissipation wall plates. (b) Effects of axial compression ratio $n$. (c) Effects of eccentricity $e$.

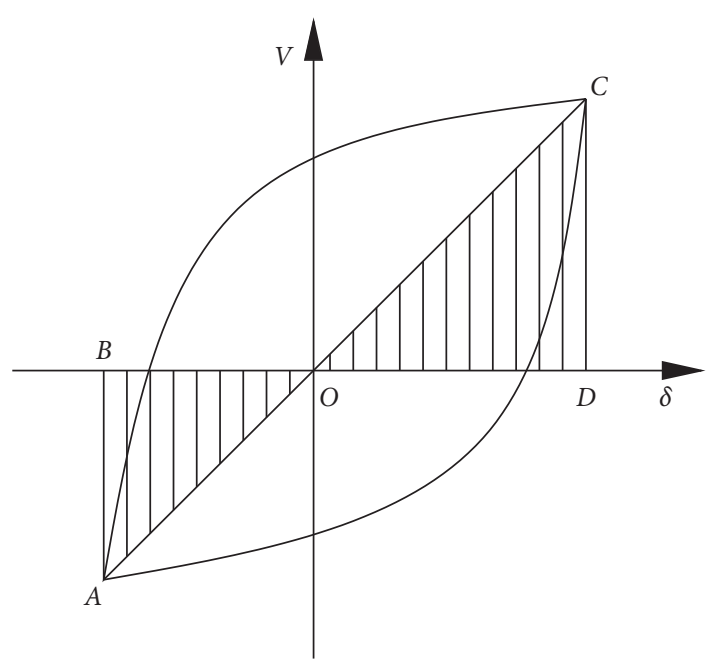

FIGURE 12: Load-displacement hysteresis loop of the pseudostatic specimen. eccentricity increased, the value of $h_{\mathrm{e}}$ decreased by $16 \%$ on average, which indicated a reduction in the energy dissipation capacity.

\section{Numerical Analysis}

4.1. Finite Element Model. A finite element model was built using ANSYS software. Steel plate was simulated by using the element Shell181. The KINH criterion was used in the model to simulate the performance of the material. The constitutive model of the material is shown in Figure 14, where the $Y$-axis represents the stress (unit: $\mathrm{MPa}$ ) and the $X$ axis represents the strain. The geometric model was meshed using an element size of $25 \mathrm{~mm}$ as the control parameter. After meshing, the finite element grid was almost square. The contact pairs were developed in the numerical simulation model so as to simulate the bolt connection between the low-yield-point steel energy dissipation wall plates and 


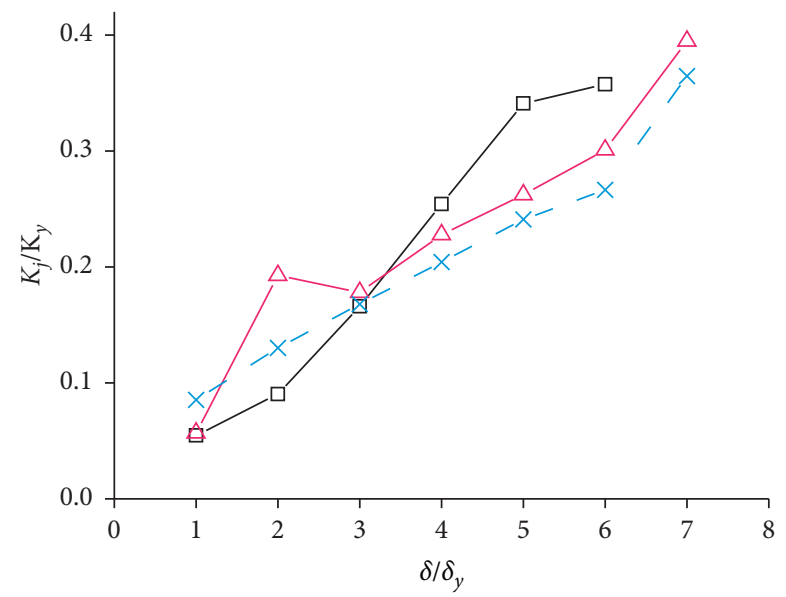

- - - I-1_without

$-\triangle-$ II-1_with

$-X-$ III-1_with

(a)
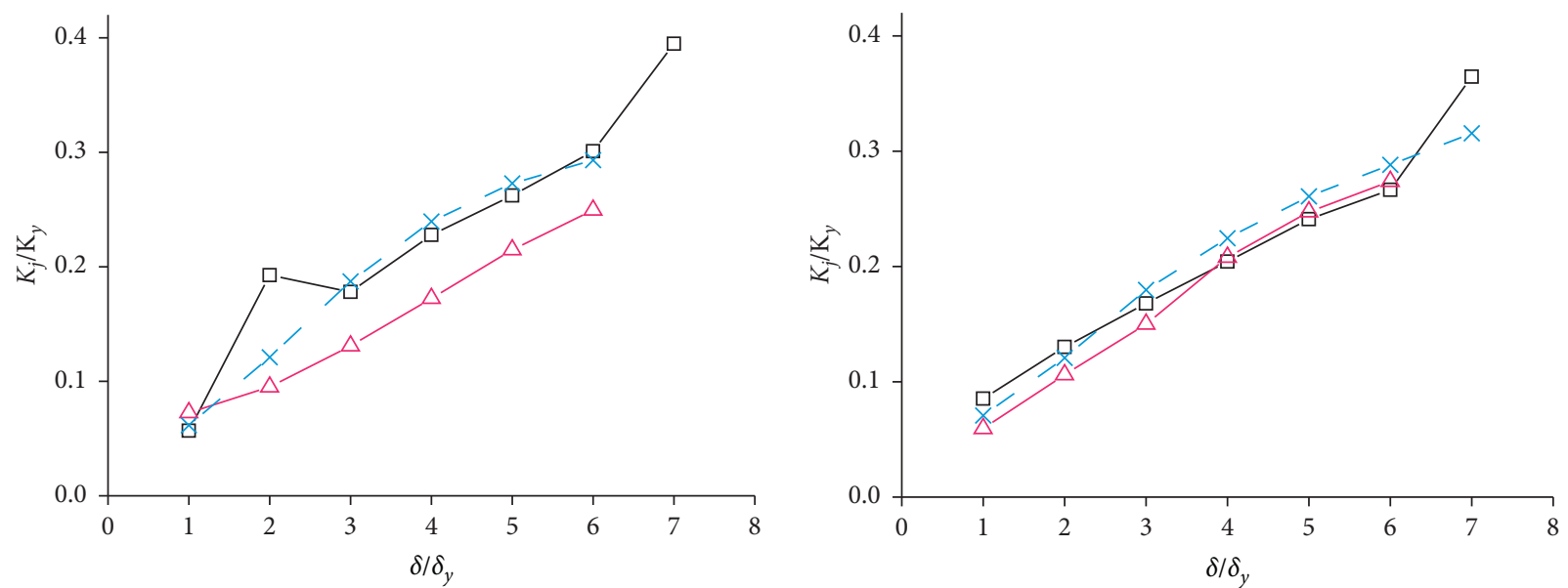

- - II- $1 \_n=0.2$

- $\square-$ III-1_n $=0.2$

$-\triangle-$ III-2_n $=0.15$

$-\triangle-$ II-2_n $=0.15$

$-X$ - III-3_n $=0.1$

(i) $e=0 \mathrm{~mm}$

(ii) $e=80 \mathrm{~mm}$

(b)

FIgURE 13: Continued. 


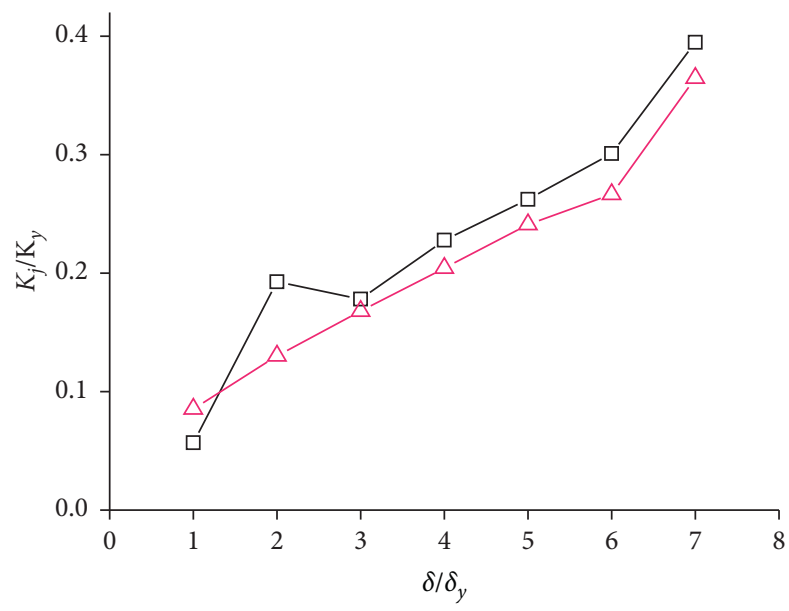

- - II-1_e $=0$

$-\triangle-$ III- $1 \_e=80$

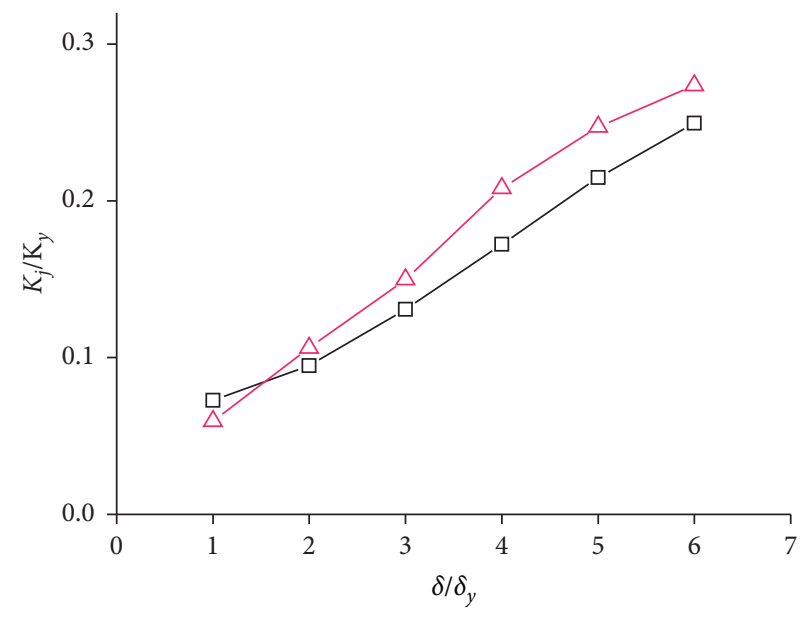

- - II-2_e $=0$

$-\triangle-$ III-2_e $=80$

(ii) $n=0.15$

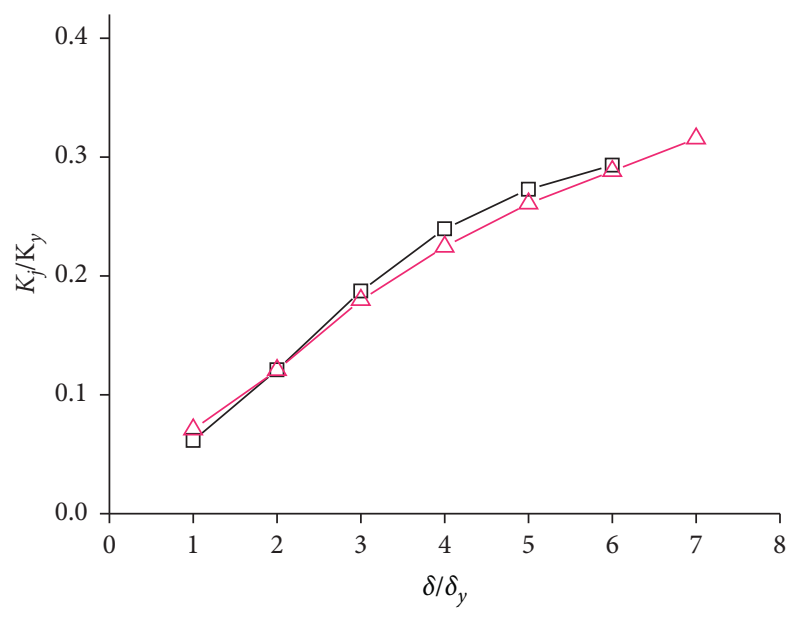

$-\square-$ II-3_e $=0$

$-\triangle-$ III-3_e $=80$

(iii) $n=0.10$

(c)

FIGURE 13: Equivalent viscous damping coefficient $h_{e}$ of the specimens. (a) Effects of installing buckling-restrained energy dissipation wall plates. (b) Effects of axial compression ratio $n$. (c) Effects of eccentricity $e$.

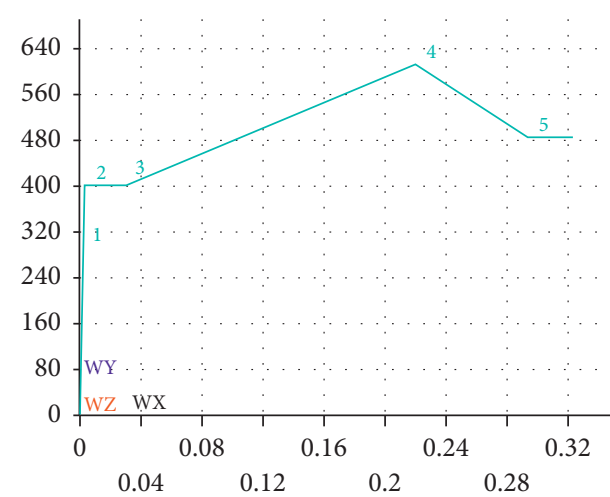

(a)

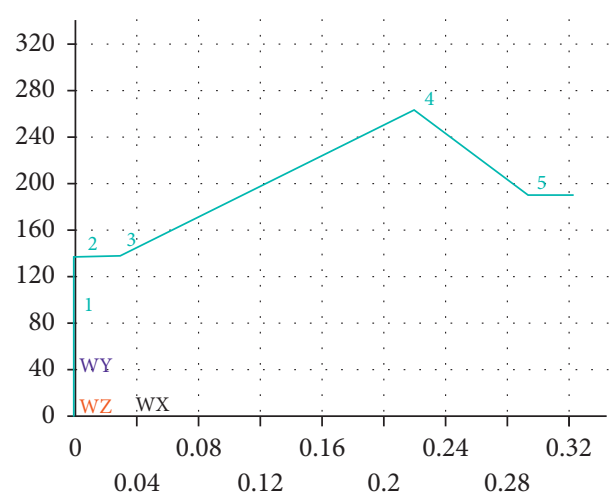

(b)

FIgURE 14: Constitutive model of steel material. (a) Steel material of Q345. (b) Low-yield-point steel of LYP100. 


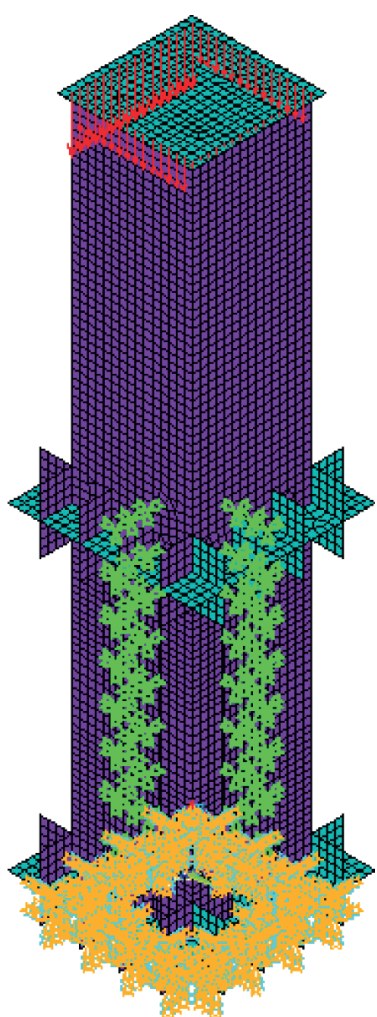

(a)

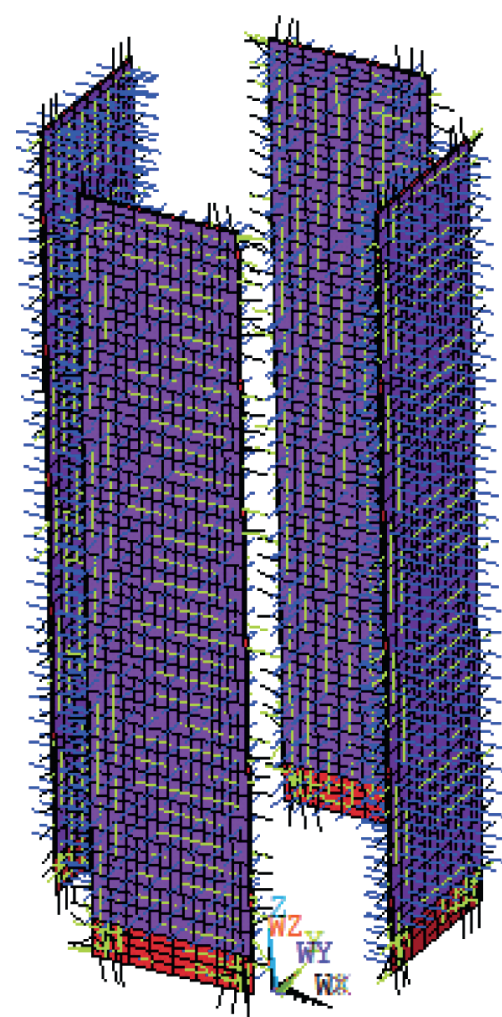

(b)

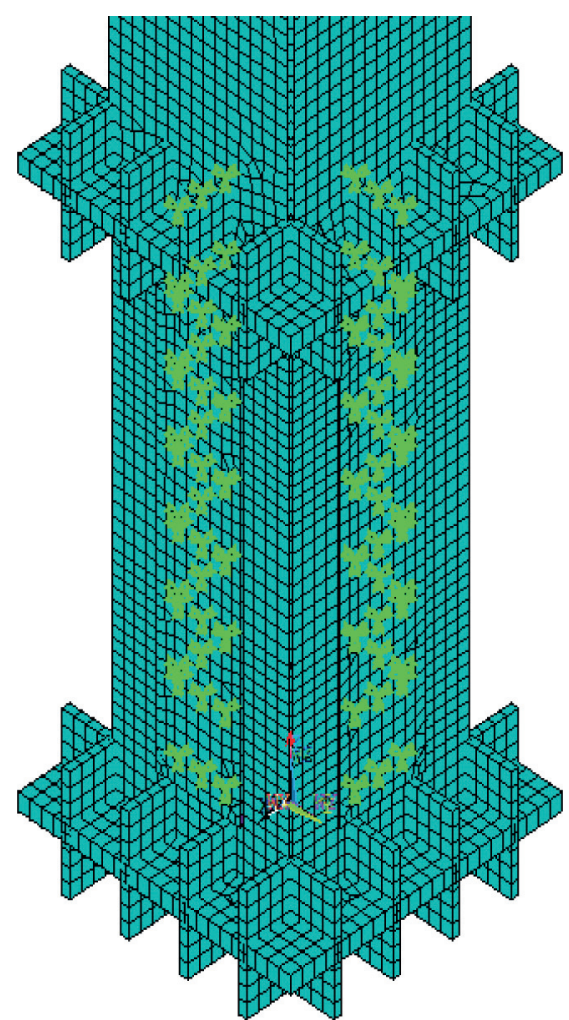

(c)

FIGURE 15: Finite element model. (a) Boundary constraints. (b) Contact pairs on LYP steel plates. (c) Simulation of bolts connection.

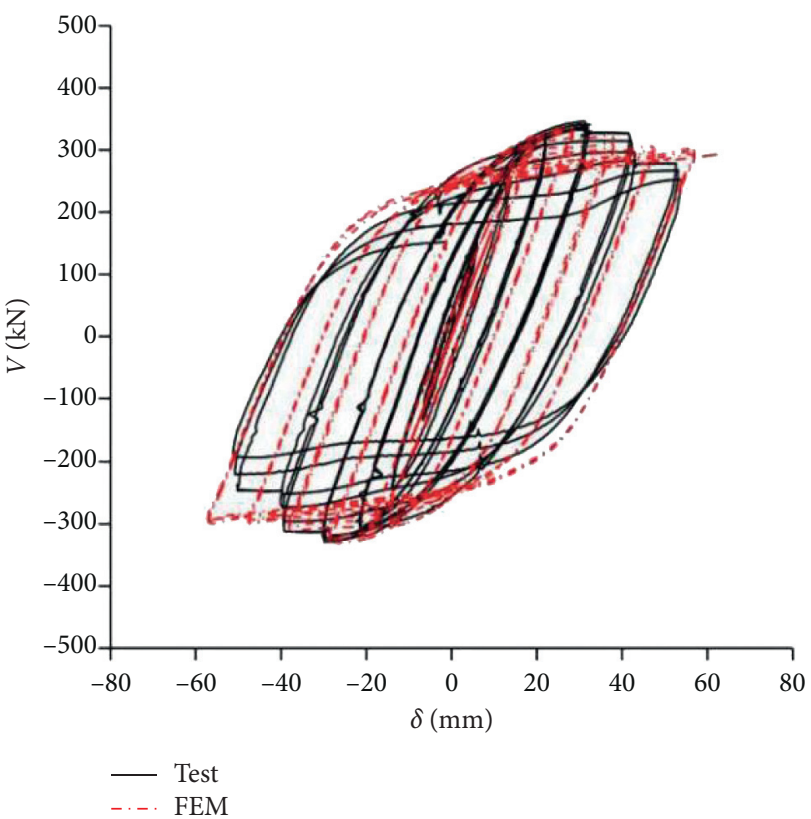

(a)

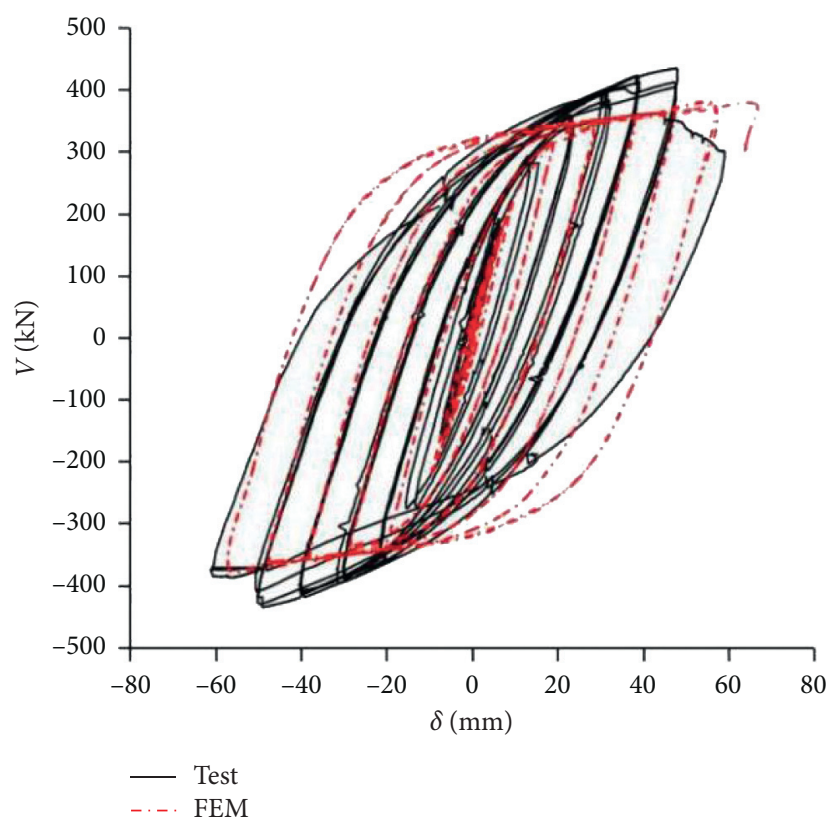

(b)

FIGURE 16: Comparison on hysteretic curves of some pseudostatic specimens. (a) Specimen I-1. (b) Specimen II-1. 


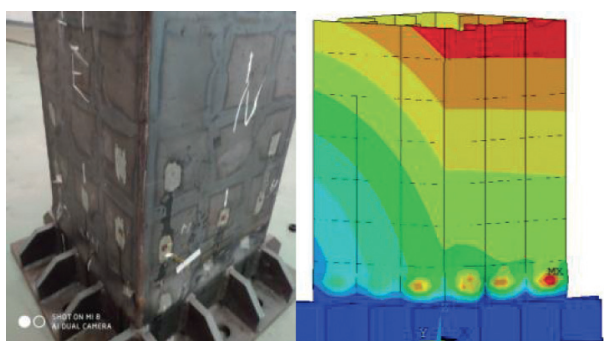

(a)

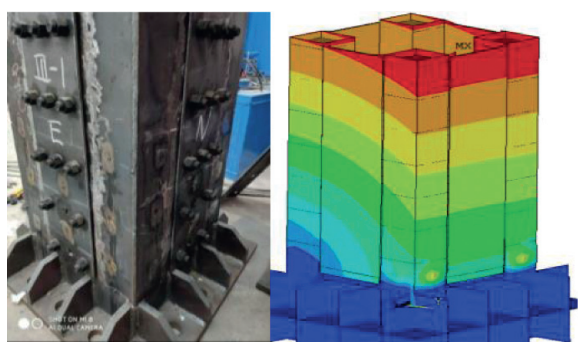

(b)

Figure 17: Comparison on failure modes of some pseudostatic specimens. (a) Specimen I-1. (b) Specimen III-1.

TABLE 4: Comparison on peak point data of pseudostatic specimens.

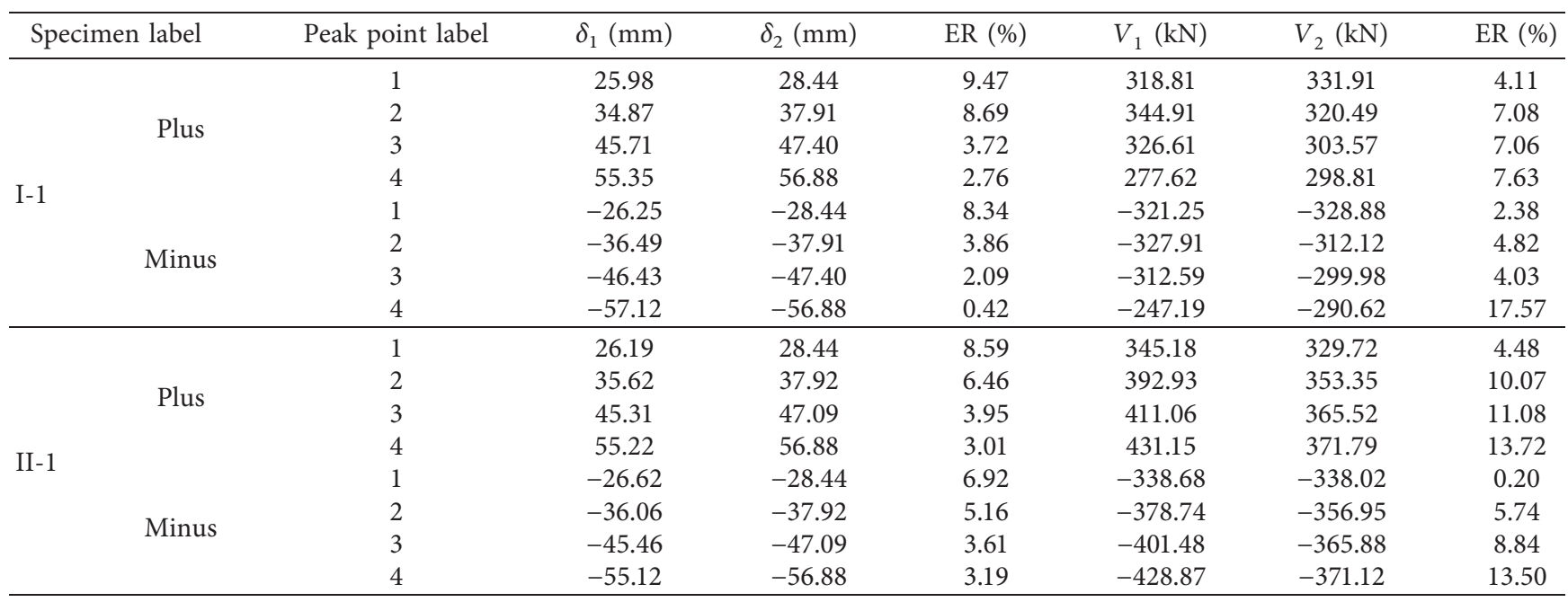

constraining steel plates on the two sides. It was also coupled with the linear displacements of the corresponding nodes on the three steel plates. Rigid connection constraint was imposed on the column bottom. An equivalent uniform linear load was applied to the corresponding positions on the column top as vertical pressure. A cyclic horizontal load was imposed on the column top by controlling the lateral displacement of the nodes on the column top. The finite element model is shown in Figure 15.

4.2. Verification of the Finite Element Model. For the purpose of verifying the accuracy of the established finite element model above, the hysteresis curve and failure mode of some specimens in the pseudostatic test were plotted and compared, as shown in Figures 16 and 17 and Table 4. It can be seen from Figures 16 and 17 that the load-displacement hysteresis curve simulated by the model matched with the experimental curve accurately. The buckling mode and position simulated by the model also agreed well with the experimental result. In Table $4, \delta_{1}$ and $\delta_{2}$ represent the displacement of each peak point obtained by experiment and simulation. $V_{1}$ and $V_{2}$ represent the horizontal load of peak point obtained by experiment and simulation, respectively. ER means the error rate of data obtained by experiment and simulation. Table 4 shows that the error rate of peak strain between simulation and experiment is less than $10 \%$, and most of the error rate of peak stress is less than $10 \%$. The finite element simulation results are basically consistent with the experimental results. It indicates that the finite element model is accurate to simulate the experimental specimen.

4.3. Specimens for Numerical Analysis. The value ranges of axial compression ratio $n$, strength $f_{1}$ of energy dissipation wall plates, spacing $D S_{1}$ between horizontal stiffening ribs, thickness $t_{1}$ of energy dissipation wall plate, and eccentricity $e$ were further expanded. Thus, 34 specimens with different combinations of the above parameters were designed. The compared specimen used for the axially compressed pseudostatic test was C-I-1. The axial compression ratio $n$ of the specimens in group I-A was chosen as $0.05,0.1,0.2$, and 0.25 , respectively. The strength $f_{1}$ of the energy dissipation wall plates in group I-B was $160 \mathrm{MPa}, 235 \mathrm{MPa}$, and $460 \mathrm{MPa}$, respectively. The spacing $D S_{1}$ between the horizontal stiffening ribs in group I-C was $160 \mathrm{~mm}, 240 \mathrm{~mm}$, and $960 \mathrm{~mm}$, respectively. Thickness $t_{1}$ of the energy dissipation wall plate in group I-D was $18 \mathrm{~mm}, 30 \mathrm{~mm}, 36 \mathrm{~mm}$, and $42 \mathrm{~mm}$, respectively. The compared specimen used for the eccentrically compressed pseudostatic test was C-II-1. For specimens in groups II-A, II-B, II-C, and II-D, the eccentricity $e$ of vertical loading on the top of the column was always $960 \mathrm{~mm}$. The other parameters designed were consistent with those for specimens in group I for the axially compressed pseudostatic 
TABle 5: The design parameters of pseudostatic specimens.

\begin{tabular}{|c|c|c|c|c|c|c|c|c|c|c|c|}
\hline Specimen label & $L(\mathrm{~mm})$ & $D L(\mathrm{~mm})$ & $t(\mathrm{~mm})$ & $b(h)(\mathrm{mm})$ & $b_{1}(\mathrm{~mm})$ & $t_{1}(\mathrm{~mm})$ & $D S_{1}(\mathrm{~mm})$ & $f(\mathrm{MPa})$ & $f_{1}(\mathrm{MPa})$ & $e(\mathrm{~mm})$ & $n$ \\
\hline C-I-1 & 8460 & 4000 & 24 & 1500 & 720 & 24 & 480 & 345 & 100 & 0 & 0.15 \\
\hline I-A-1 & 8460 & 4000 & 24 & 1500 & 720 & 24 & 480 & 345 & 100 & 0 & 0.05 \\
\hline I-A-2 & 8460 & 4000 & 24 & 1500 & 720 & 24 & 480 & 345 & 100 & 0 & 0.1 \\
\hline I-A-3 & 8460 & 4000 & 24 & 1500 & 720 & 24 & 480 & 345 & 100 & 0 & 0.2 \\
\hline I-A-4 & 8460 & 4000 & 24 & 1500 & 720 & 24 & 480 & 345 & 100 & 0 & 0.25 \\
\hline I-B-1 & 8460 & 4000 & 24 & 1500 & 720 & 24 & 480 & 345 & 160 & 0 & 0.15 \\
\hline I-B-2 & 8460 & 4000 & 24 & 1500 & 720 & 24 & 480 & 345 & 235 & 0 & 0.15 \\
\hline I-B-3 & 8460 & 4000 & 24 & 1500 & 720 & 24 & 480 & 345 & 460 & 0 & 0.15 \\
\hline I-C-1 & 8460 & 4000 & 24 & 1500 & 720 & 24 & 160 & 345 & 100 & 0 & 0.15 \\
\hline I-C-2 & 8460 & 4000 & 24 & 1500 & 720 & 24 & 240 & 345 & 100 & 0 & 0.15 \\
\hline I-C-3 & 8460 & 4000 & 24 & 1500 & 720 & 24 & 960 & 345 & 100 & 0 & 0.15 \\
\hline I-D-1 & 8460 & 4000 & 24 & 1500 & 720 & 18 & 480 & 345 & 100 & 0 & 0.15 \\
\hline I-D-2 & 8460 & 4000 & 24 & 1500 & 720 & 30 & 480 & 345 & 100 & 0 & 0.15 \\
\hline I-D-3 & 8460 & 4000 & 24 & 1500 & 720 & 36 & 480 & 345 & 100 & 0 & 0.15 \\
\hline I-D-4 & 8460 & 4000 & 24 & 1500 & 720 & 42 & 480 & 345 & 100 & 0 & 0.15 \\
\hline C-II-1 & 8460 & 4000 & 24 & 1500 & 720 & 24 & 480 & 345 & 100 & 960 & 0.15 \\
\hline II-A-1 & 8460 & 4000 & 24 & 1500 & 720 & 24 & 480 & 345 & 100 & 960 & 0.05 \\
\hline II-A-2 & 8460 & 4000 & 24 & 1500 & 720 & 24 & 480 & 345 & 100 & 960 & 0.1 \\
\hline II-A-3 & 8460 & 4000 & 24 & 1500 & 720 & 24 & 480 & 345 & 100 & 960 & 0.2 \\
\hline II-A-4 & 8460 & 4000 & 24 & 1500 & 720 & 24 & 480 & 345 & 100 & 960 & 0.25 \\
\hline II-B-1 & 8460 & 4000 & 24 & 1500 & 720 & 24 & 480 & 345 & 160 & 960 & 0.15 \\
\hline II-B-2 & 8460 & 4000 & 24 & 1500 & 720 & 24 & 480 & 345 & 235 & 960 & 0.15 \\
\hline II-B-3 & 8460 & 4000 & 24 & 1500 & 720 & 24 & 480 & 345 & 460 & 960 & 0.15 \\
\hline II-C-1 & 8460 & 4000 & 24 & 1500 & 720 & 24 & 160 & 345 & 100 & 960 & 0.15 \\
\hline II-C-2 & 8460 & 4000 & 24 & 1500 & 720 & 24 & 240 & 345 & 100 & 960 & 0.15 \\
\hline II-C-3 & 8460 & 4000 & 24 & 1500 & 720 & 24 & 960 & 345 & 100 & 960 & 0.15 \\
\hline II-D-1 & 8460 & 4000 & 24 & 1500 & 720 & 18 & 480 & 345 & 100 & 960 & 0.15 \\
\hline II-D-2 & 8460 & 4000 & 24 & 1500 & 720 & 30 & 480 & 345 & 100 & 960 & 0.15 \\
\hline II-D-3 & 8460 & 4000 & 24 & 1500 & 720 & 36 & 480 & 345 & 100 & 960 & 0.15 \\
\hline II-D-4 & 8460 & 4000 & 24 & 1500 & 720 & 42 & 480 & 345 & 100 & 960 & 0.15 \\
\hline II-E-1 & 8460 & 4000 & 24 & 1500 & 720 & 24 & 480 & 345 & 100 & 320 & 0.15 \\
\hline II-E-2 & 8460 & 4000 & 24 & 1500 & 720 & 24 & 480 & 345 & 100 & 640 & 0.15 \\
\hline II-E-3 & 8460 & 4000 & 24 & 1500 & 720 & 24 & 480 & 345 & 100 & 1280 & 0.15 \\
\hline II-E-4 & 8460 & 4000 & 24 & 1500 & 720 & 24 & 480 & 345 & 100 & 1600 & 0.15 \\
\hline
\end{tabular}

Note. $\mathrm{f}_{1}$ is the strength of the energy dissipation wall plate; meaning of other parameters is the same as in Table 1.

test. For group II-E, the eccentricity $e$ of the specimens was chosen as $320 \mathrm{~mm}, 640 \mathrm{~mm}, 1280 \mathrm{~mm}$, and $1600 \mathrm{~mm}$, respectively. The parameter ranges adopted for the specimens used for numerical analysis are shown in Table 5.

4.4. Parameter Analysis and Discussion. The skeleton curves of specimens in the numerical analysis were extracted as shown in Figure 18 to discuss the influence of the axial compression ratio, strength of energy dissipation wall plate, spacing between horizontal stiffening ribs, thickness of energy dissipation wall plate, and eccentricity on the seismic behavior of the novel box-shaped steel bridge pier. In Figure 18(a), the bearing capacity and deformation capacity of axially compressed specimens are greatly affected by the axial compression ratio, when $n$ increased from 0.05 to 0.25 , and the deformation capacity of specimen decreased by $52.6 \%$. In Figure 18(b), strength of the energy dissipation wall plate had a significant impact on the proposed steel bridge pier's bearing capacity and deformation capacity. The bearing capacity of the novel box-shaped steel bridge pier can be improved effectively with higher strength of the energy dissipation wall plates. When the material of the energy dissipation wall plate was changed from LYP100 to Q460, the load-bearing capacity of the specimen increased by $46.3 \%$ at most. However, at the later stage of loading, a higher strength of the energy dissipation wall plate led to more conspicuous stiffness and strength degradation of the specimen. According to Figure 18(c), the spacing between the horizontal stiffening ribs had little impact on the bearing capacity and deformation capacity of the novel steel box bridge pier. When $D S_{1}$ was increased from $160 \mathrm{~mm}$ to $960 \mathrm{~mm}$, the load-bearing capacity of the specimen decreased by $11.4 \%$, and specimen's deformation capacity remained almost unchanged. As shown in Figure 18(d), the thickness of the energy dissipation wall plates plays an important role in influencing the seismic performance of the novel box-shaped steel bridge pier. With the thicker energy dissipation wall plate, the bearing capacity of the steel box bridge pier would be increased by $20.1 \%$ at most. As shown 


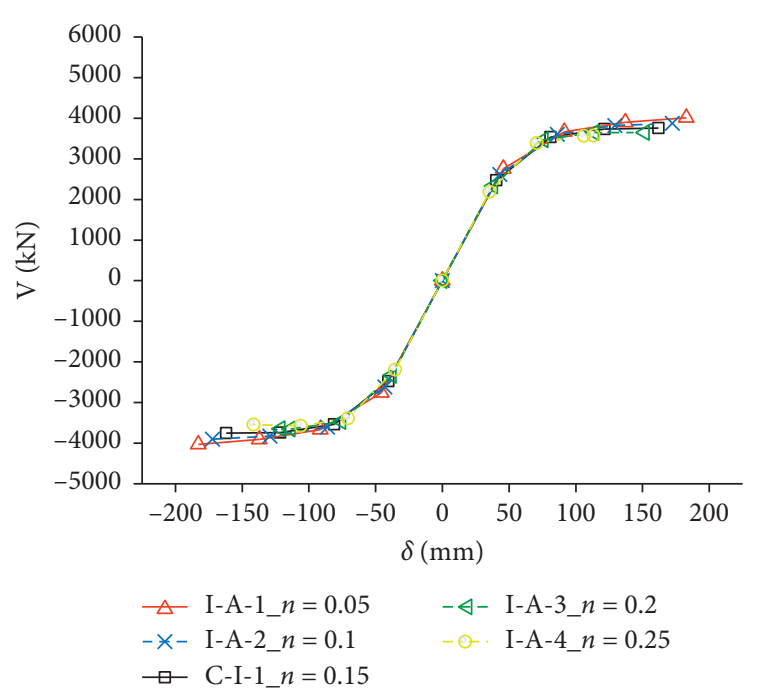

(i) $e=0 \mathrm{~mm}$

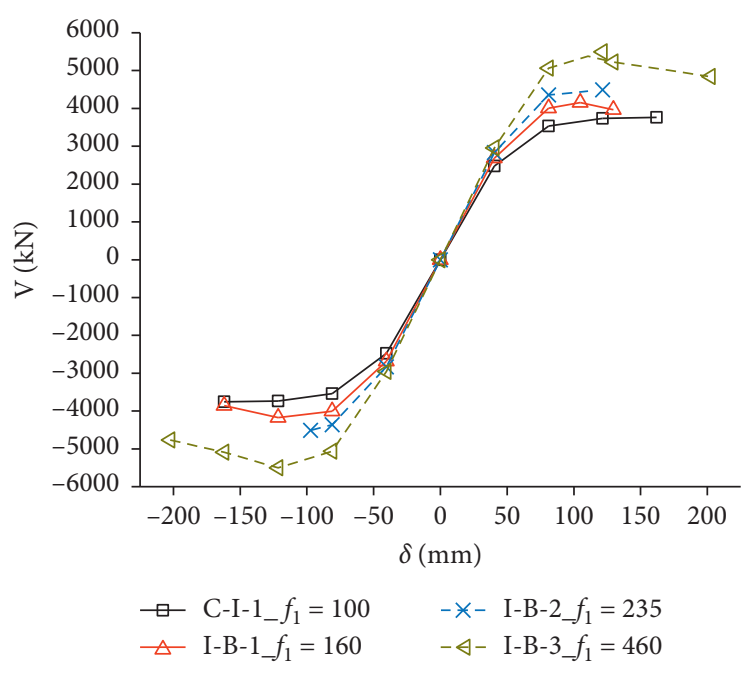

(i) $e=0 \mathrm{~mm}$

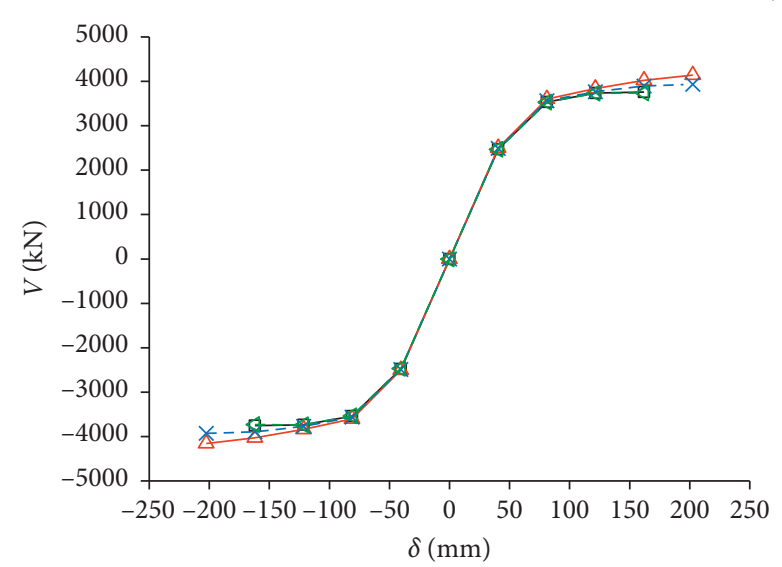

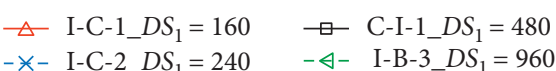

(i) $e=0 \mathrm{~mm}$

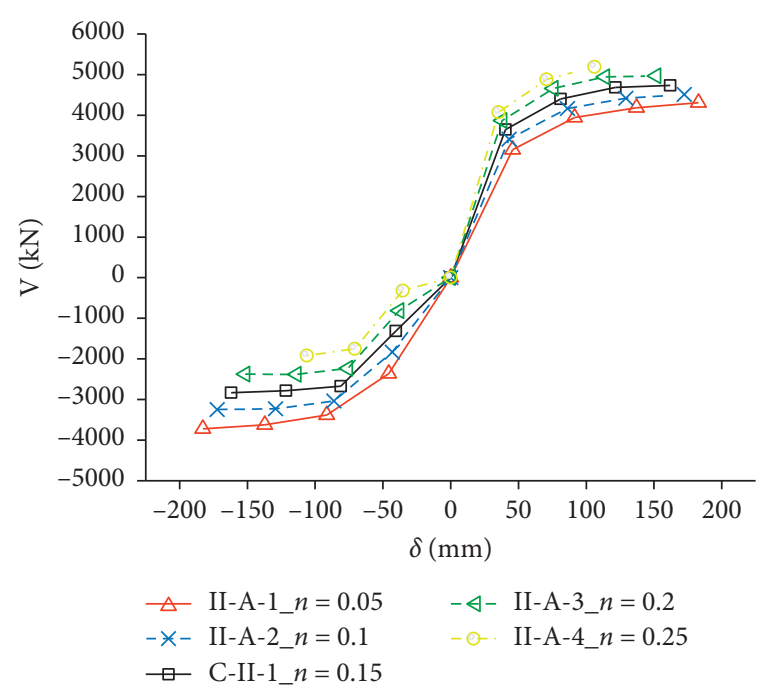

(ii) $e=960 \mathrm{~mm}$

(a)

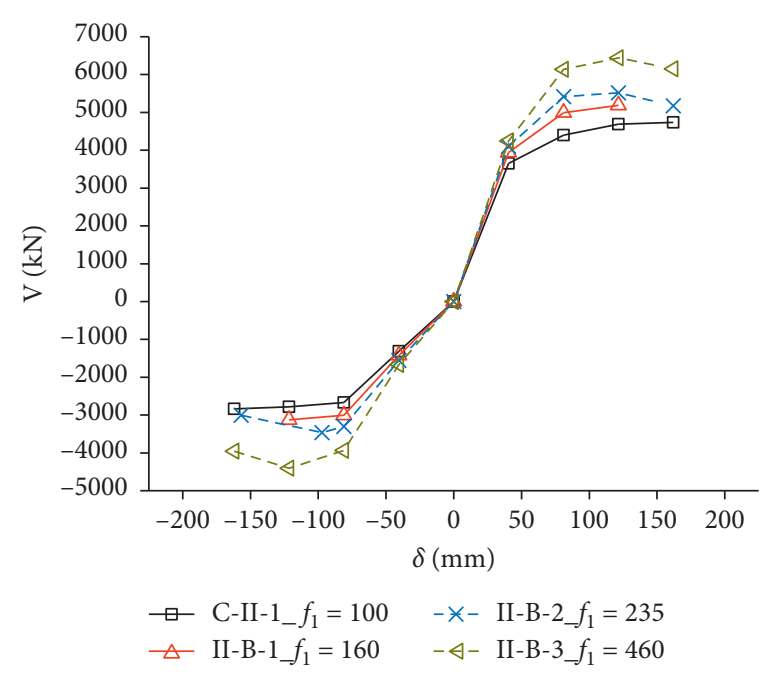

(ii) $e=960 \mathrm{~mm}$

(b)

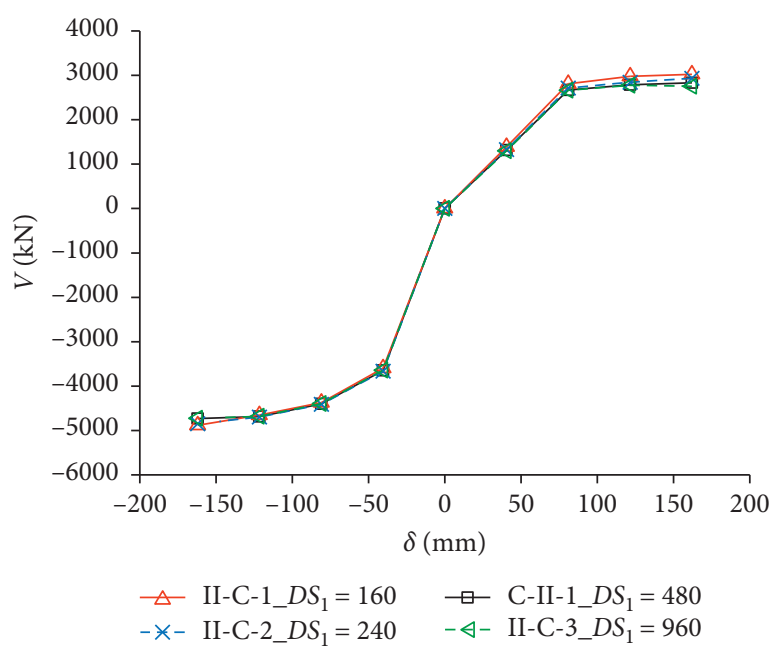

(ii) $e=960 \mathrm{~mm}$

(c)

FIgure 18: Continued. 


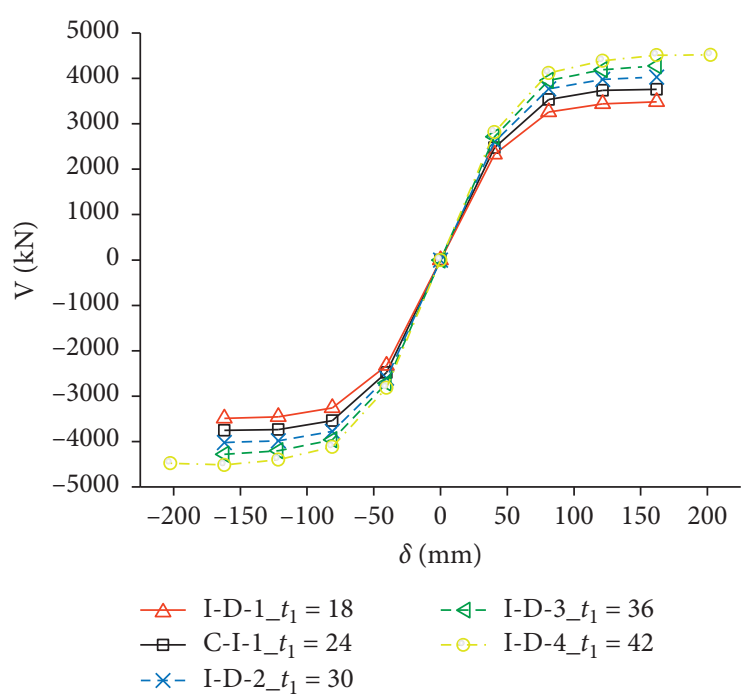

(i) $e=0 \mathrm{~mm}$

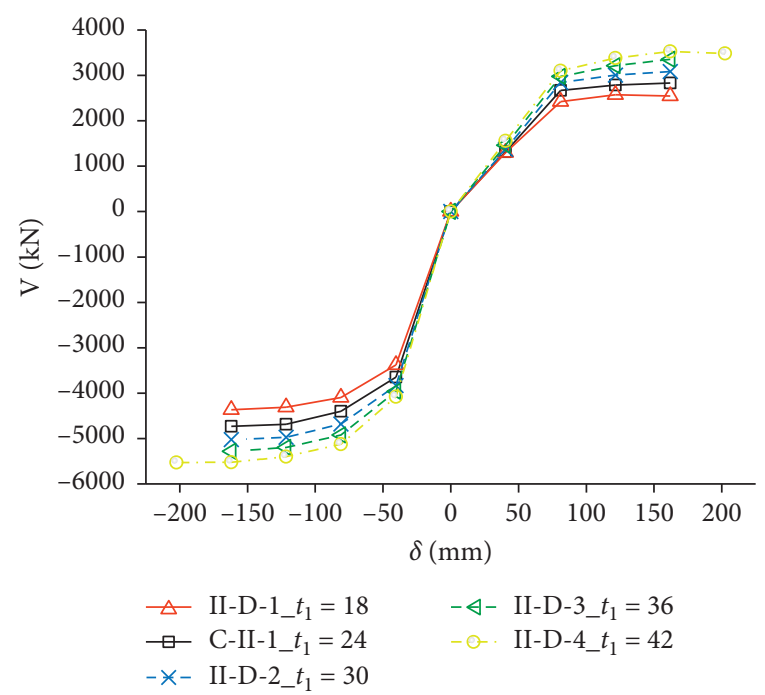

(ii) $e=960 \mathrm{~mm}$

(d)

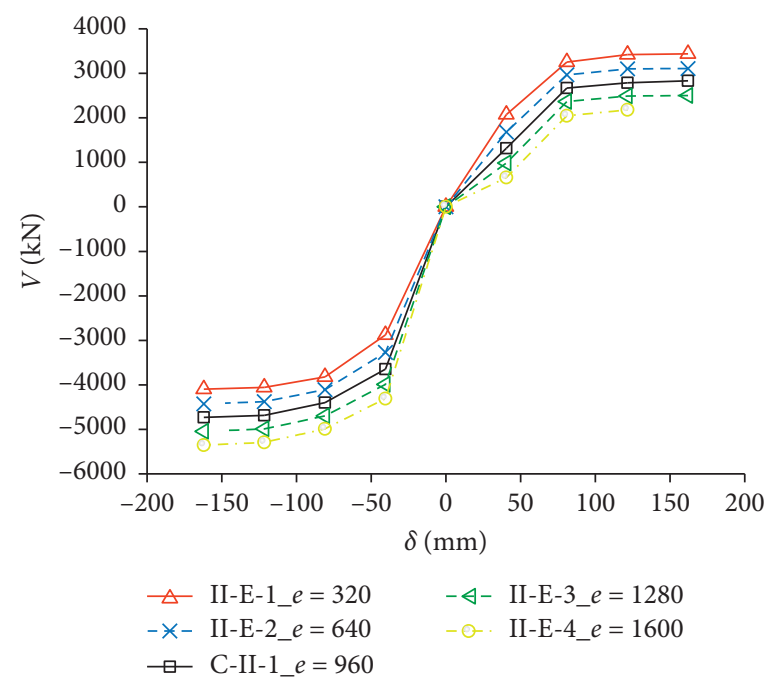

(e)

FIGURE 18: Skeleton curves of numerical specimens. (a) Effects of axial compression ratio ( $n$ ). (b) Effects of strength of energy dissipation wall plate $\left(f_{1}\right)$. (c) Effects of spacing between horizontal stiffening ribs $\left(D S_{1}\right)$. (d) Effects of thickness of energy dissipation wall plate $\left(t_{1}\right)$. (e) Effects of eccentricity $(e)$.

in Figure 18(e), the skeleton curve showed a downward shift due to the eccentricity. The higher the eccentricity, the lower the deformation capacity of the specimen.

\section{Design Formula}

Based on the results of the pseudostatic experiment and numerical simulation, design formula (4) for the novel steel box bridge pier with the energy dissipation wall plates under cyclic loading was established. The results have shown that the bearing capacity of the structure is greatly influenced by the axial compression ratio. In formula (4), the variables $\alpha$ and $\beta$ are all functions of the axial compression ratio $n$; the variable $\gamma$ is the function of strength $f_{1}$ of the energy dissipation wall plate, spacing $D S_{1}$ between the horizontal stiffening ribs and thickness $t_{1}$ of the energy dissipation wall plate; $N$ and $M$ are the maximum compression and maximum bending moment of the column, respectively; $N_{\mathrm{E}}$ is the Euler force of the cross section, and $M_{\mathrm{P}}$ means the plastic bending moment of the cross section; $E$ is the elastic modulus of the steel; $A$ is the area of box section; $\lambda_{\mathrm{z}}$ is the slenderness of the steel box bridge steel around the minor axis; $t$ is the thickness of the flange plate; $b$ is the width of the flange plate; $h_{0}$ is the height of the web plate; $f_{\mathrm{y}}$ is the strength of the ordinary steel wall plate; $L$ means the calculated length of the box-shaped steel bridge pier. The results of the pseudostatic experiment and numerical simulation were analyzed for the steel box bridge pier. The relation expressions of parameters $\alpha, \beta$, and $\gamma$ were fitted by regression: 


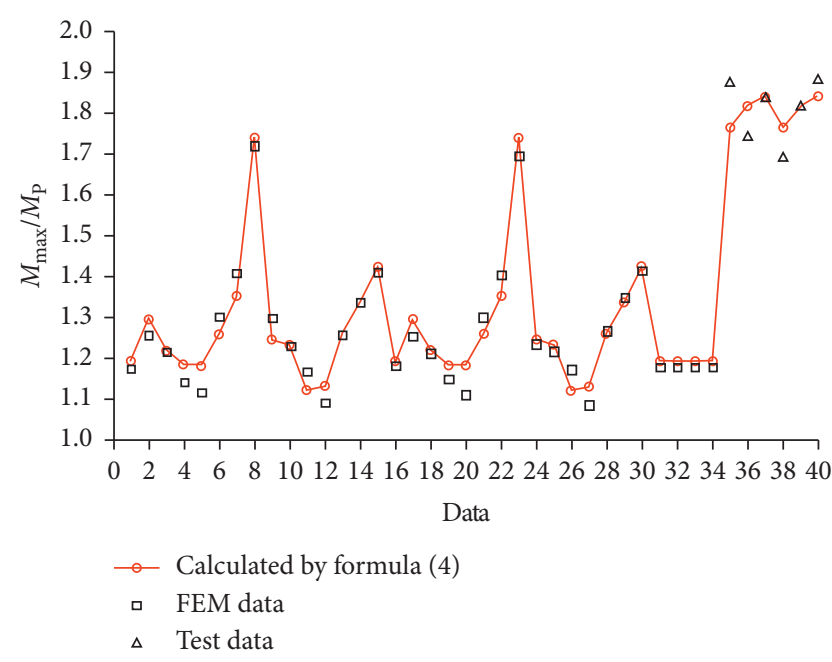

Figure 19: Results by formula (4), the pseudostatic test, and finite element analysis.

$$
\alpha\left(\frac{N}{N_{\mathrm{E}}}\right)^{\beta}+\gamma\left(\frac{M}{M_{\mathrm{P}}}\right)=1,
$$

where $N_{\mathrm{E}}=\pi^{2} \mathrm{EA} / \lambda_{z}^{2} ; M_{\mathrm{p}}=\left(0.5 t h_{0}^{2}+t b h_{0}\right) f_{\mathrm{y}} ; \alpha=(-51.427-$ $0.029 n L) ; \beta=(0.795+0.00121 n L)$; and $\gamma=\left(1.050-0.07396 f_{1} /\right.$ $\left.100+0.05424 D S_{1} / 480-0.1824 t_{1} / 24\right)$.

19 shows the comparison of the results by calculation using formula (4), the pseudostatic test, and finite element analysis. In Figure 19, the $Y$-axis represented the ratio of maximum bending moment $M_{\max }$ to plastic bending moment $M_{\mathrm{p}}$ of cross section; the $X$-axis represented the number of data points. According to Figure 19, the error in formula (4) with respect to the pseudostatic test and finite element simulation remained at $\pm 6.5 \%$, which indicated the high accuracy of obtained design formula (4).

\section{Conclusions}

In the present study, a pseudostatic test and finite element simulation analysis were carried out for the novel steel box bridge pier with recoverable function. The following conclusions were reached.

(1) Failure of specimens in the pseudostatic test all occurred in the energy dissipation zone at the base of the specimen, while the upper column and the rigid base can be repeatedly used. This indicated that by replacing the damaged energy dissipation zone at the base, the seismic design of a steel box bridge pier with earthquake-resilient function can be achieved.

(2) Failure mode of specimens in the pseudostatic test was divided into two types: the first was the local buckling of the energy dissipation wall plates of the specimen, where plastic deformation was predominant; the other was weld failure or fracture of the wall plate at the corner in the energy dissipation zone.

(3) Axial compression ratio has an important influence on the seismic performance of the steel box bridge pier. As compared with the specimens in the axial compression test, the axial compression ratio of specimen had a relatively larger impact on the bearing capacity and deformation capacity of specimens in the eccentric compression test.

(4) The strength of the energy dissipation wall plate influenced the specimen's bearing capacity and deformation capacity in a considerable way. The higher the strength of the energy dissipation wall plate, the larger the carrying capacity of the bridge pier; however, at the later loading stage, the higher strength of the energy dissipation wall plate directly led to considerable strength and stiffness degradation.

(5) Spacing between the horizontal stiffening ribs had relatively less impact on the bearing capacity and deformation capacity of the proposed novel bridge pier.

(6) Thickness of the energy dissipation wall plate is an important factor that influences the seismic performance of the novel box-shaped steel bridge pier. The bearing capacity and deformation capacity of such steel piers would be improved by the thicker the energy dissipation wall plate.

(7) There was a downward shift in the skeleton curve of the specimen due to eccentricity. The larger the eccentricity, the worse the deformation capacity of the specimen.

(8) The design formula for the novel steel box bridge pier under cyclic loading was proposed based on the results of the pseudostatic experiment and numerical simulation analysis.

\section{Data Availability}

The data used to support the findings of this study are available from the corresponding author upon request.

\section{Conflicts of Interest}

The authors declare no conflicts of interest.

\section{Acknowledgments}

This research work was supported by the National Natural Science Foundation of China (no. 51778248), Natural Science Foundation of Fujian Province (no. 2018J01075), Promotion Program for Young and Middle-Aged Teacher in Science and Technology Research of Huaqiao University (no. ZQN-PY312), and Research Trained Fund for Outstanding Young Researcher in Higher Education Institutions of Fujian Province. Besides, the first author would like to appreciate the China Scholarship Council for sponsoring the visit at the University of New South Wales under the grant no. 201807540009. The tests were completed in the Key Laboratory for Structural Engineering and Disaster Prevention of Fujian Province. The support provided by the laboratory staff is gratefully acknowledged. 


\section{References}

[1] Q. Al-Kaseasbeh and I. H. P. Mamaghani, "Buckling strength and ductility evaluation of thin-walled steel stiffened square box columns with uniform and graded thickness under cyclic loading," Engineering Structures, vol. 186, pp. 498-507, 2019.

[2] L. Kang, M. Suzuki, and H. B. Ge, "A study on application of high strength steel SM570 in bridge piers with stiffened box section under cyclic loading," Steel and Composite Structures, vol. 26, no. 5, pp. 583-594, 2018.

[3] S. Chen, X. Xie, and H. Zhuge, "Hysteretic model for steel piers considering the local buckling of steel plates," Engineering Structures, vol. 183, pp. 303-318, 2019.

[4] K. Nishikawa, S. Yamamoto, T. Natori, K. Terao, H. Yasunami, and M. Terada, "Retrofitting for seismic upgrading of steel bridge columns," Engineering Structures, vol. 20, no. 4-6, pp. 540-551, 1998.

[5] H.-L. Hsu and D.-L. Chang, "Upgrading the performance of steel box piers subjected to earthquakes," Journal of Constructional Steel Research, vol. 57, no. 9, pp. 945-958, 2001.

[6] R. E. S. Ismail, F. A. Fathelbab, H. A. Zien Eldin, and S. I. Zenhom, "Numerical investigations on dynamic performance of stiffened box steel bridge piers," International Journal of Steel Structures, vol. 12, no. 2, pp. 139-155, 2012.

[7] T. Aoki, T. Takaku, Y. Fukumoto, and K. S. A. Susantha, "Experimental investigation for seismic performance of framed structures having longitudinally profiled plates," Journal of Constructional Steel Research, vol. 64, no. 7-8, pp. 875-881, 2008.

[8] S. Gao, T. Usami, and H. Ge, "Eccentrically loaded steel columns under cyclic in-plane loading," Journal of Structural Engineering, vol. 126, no. 8, pp. 964-973, 2000.

[9] H. Ge and L. Kang, "Ductile crack initiation and propagation in steel bridge piers subjected to random cyclic loading," Engineering Structures, vol. 59, pp. 809-820, 2014.

[10] T. Usami, H. B. Ge, and K. Saizuka, "Behavior of partially concrete-filled steel bridge piers under cyclic and dynamic loading," Journal of Constructional Steel Research, vol. 41, no. 2-3, pp. 121-136, 1998.

[11] T. Usami, Y. Zheng, and H. B. Ge, "Recent research developments in stability and ductility of steel bridge structures," Journal of Constructional Steel Research, vol. 55, no. 1-3, pp. 183-209, 2000.

[12] H. B. Ge, K. A. S. Susantha, Y. Satake, and T. Usami, "Seismic demand predictions of concrete-filled steel box columns," Engineering Structures, vol. 25, no. 3, pp. 337-345, 2003.

[13] Y. Goto, K. Mizuno, and G. Prosenjit Kumar, "Nonlinear finite element analysis for cyclic behavior of thin-walled stiffened rectangular steel columns with in-filled concrete," Journal of Structural Engineering, vol. 138, no. 5, pp. 571-584, 2012.

[14] K. A. S. Susantha, H. Ge, and T. Usami, "Cyclic analysis and capacity prediction of concrete-filled steel box columns," Earthquake Engineering and Structural Dynamics, vol. 31, no. 2, pp. 195-216, 2010.

[15] K. Nakanishi, T. Kitada, and H. Nakai, "Experimental study on ultimate strength and ductility of concrete filled steel columns under strong earthquake," Journal of Constructional Steel Research, vol. 51, no. 3, pp. 297-319, 1999.

[16] T. Yamao, K. Iwatsubo, T. Yamamuro, M. Ogushi, and S. Matsumura, "Steel bridge piers with inner cruciform plates under cyclic loading," Thin-Walled Structures, vol. 40, no. 2, pp. 183-197, 2002.
[17] J. Dang and T. Aoki, "Bidirectional loading hybrid tests of square cross-sections of steel bridge piers," Earthquake Engineering \& Structural Dynamics, vol. 42, no. 8, pp. 1111-1130, 2013.

[18] S. El-Bahey and M. Bruneau, "Bridge piers with structural fuses and bi-steel columns. I: experimental testing," Journal of Bridge Engineering, vol. 17, no. 1, pp. 25-35, 2012.

[19] S. El-Bahey and M. Bruneau, "Bridge piers with structural fuses and bi-steel columns. II: analytical investigation," Journal of Bridge Engineering, vol. 17, no. 1, pp. 36-46, 2012.

[20] K. A. S. Susantha, T. Aoki, T. Kumano, and K. Yamamoto, "Applicability of low-yield-strength steel for ductility improvement of steel bridge piers," Engineering Structures, vol. 27, no. 7, pp. 1064-1073, 2005.

[21] S.-J. Chen and J. Chen, "Steel bridge columns with pre-selected plastic zone for seismic resistance," Thin-Walled Structures, vol. 47, no. 1, pp. 31-38, 2009.

[22] T. Kitada, M. Matsumura, and Y. Otoguro, "Seismic retrofitting techniques using an energy absorption segment for steel bridge piers," Engineering Structures, vol. 25, no. 5, pp. 621-635, 2003.

[23] H. Li, J. Luo, F. Han, and J. Luo, "Experimental study on seismic behavior of new steel box bridge piers with embedded energy dissipation shells," International Journal of Steel Structures, vol. 19, no. 3, pp. 952-969, 2019.

[24] H. Li, K. Lv, and R. Cui, "Seismic behaviour of eccentrically compressed steel-box bridge-pier columns with embedded energy-dissipating shell plates," Bulletin of Earthquake Engineering, vol. 18, no. 7, pp. 3401-3432, 2020.

[25] Z.-q. Jiang, X.-F. Yang, C. Dou, C. Li, and A.-l. Zhang, "Cyclic testing of replaceable damper: earthquake-resilient prefabricated column-flange beam-column joint," Engineering Structures, vol. 183, pp. 922-936, 2019.

[26] Z.-q. Jiang, C. Dou, A.-l. Zhang, Q. Wang, and Y.-x. Wu, "Experimental study on earthquake-resilient prefabricated cross joints with L-shaped plates," Engineering Structures, vol. 184, pp. 74-84, 2019.

[27] C. C. Chen and T. Sudibyo, "Effect of intermediate stiffeners on the behaviors of partially concrete encased steel beams," Advances in Civil Engineering, vol. 2018, Article ID 8672357, 13 pages, 2018.

[28] J. F. Choo, Y. C. Choi, S. J. Kwon et al., "Low-cycle flexural fatigue behavior of concrete beam reinforced with hybrid FRP-steel rebar," Advances in Civil Engineering, vol. 2018, Article ID 6986047, 13 pages, 2018.

[29] JGJ/T 101-2015, Specification for Seismic Test of Buildings, China Architecture \& Building Press, Beijing, China, 2015. 